\title{
Bacterial Plasminogen Receptors Utilize Host Plasminogen System for Effective Invasion and Dissemination
}

\author{
Sarbani Bhattacharya, ${ }^{1}$ Victoria A. Ploplis, ${ }^{1,2}$ and Francis J. Castellino ${ }^{1,2}$ \\ ${ }^{1}$ W. M. Keck Center for Transgene Research, University of Notre Dame, Notre Dame, IN 46556, USA \\ ${ }^{2}$ Department of Chemistry and Biochemistry, University of Notre Dame, Notre Dame, IN 46556, USA
}

Correspondence should be addressed to Francis J. Castellino, fcastell@nd.edu

Received 5 April 2012; Revised 24 July 2012; Accepted 13 August 2012

Academic Editor: David M. Waisman

Copyright ( 92012 Sarbani Bhattacharya et al. This is an open access article distributed under the Creative Commons Attribution License, which permits unrestricted use, distribution, and reproduction in any medium, provided the original work is properly cited.

\begin{abstract}
In order for invasive pathogens to migrate beyond the site of infection, host physiological barriers such as the extracellular matrix, the basement membrane, and encapsulating fibrin network must be degraded. To circumvent these impediments, proteolytic enzymes facilitate the dissemination of the microorganism. Recruitment of host proteases to the bacterial surface represents a particularly effective mechanism for enhancing invasiveness. Plasmin is a broad spectrum serine protease that degrades fibrin, extracellular matrices, and connective tissue. A large number of pathogens express plasminogen receptors which immobilize plasmin(ogen) on the bacterial surface. Surface-bound plasminogen is then activated by plasminogen activators to plasmin through limited proteolysis thus triggering the development of a proteolytic surface on the bacteria and eventually assisting the spread of bacteria. The host hemostatic system plays an important role in systemic infection. The interplay between hemostatic processes such as coagulation and fibrinolysis and the inflammatory response constitutes essential components of host defense and bacterial invasion. The goal of this paper is to highlight mechanisms whereby pathogenic bacteria, by engaging surface receptors, utilize and exploit the host plasminogen and fibrinolytic system for the successful dissemination within the host.
\end{abstract}

\section{Introduction}

Bacterial invasion is generally mediated by the bacterial surface and secreted products which often function to circumvent host innate and acquired defense systems. Evasion of host immune response and production of invasive molecules are often critical first steps for initiating systemic diseases. The host hemostatic system plays an important role in systemic infection and bacterial pathogenesis. Hemostatic processes such as coagulation and fibrin deposition, as a result of inflammation, are an essential part of the host defense system. Invasive bacterial pathogens, however, have developed a variety of strategies to elude the host line of defense and gain entry into the surrounding host tissue. The ability to degrade tissue barriers formed by extracellular matrices (ECM) and basement membranes (BM) is one of the most important factors in the pathogenesis of bacterial infection. Degradation of this network by secreted bacterial proteases leads to tissue and structural damage and thereby enhances bacterial invasiveness into the host body. However, a number of invasive bacteria like Streptococcus, Haemophilus, Neisseria and most enteric bacteria like E. coli are extracellular pathogens and produce low levels of proteases. Consequently, degradation and penetration through this network of membranes require the use of different mechanisms for invasion. A number of these mechanisms rely on the interaction with protease-dependent cascade systems of their host which include fibrinolysis, coagulation, phagocytosis, and complement activation. The mammalian fibrinolytic system which constitutes dissolution of thrombus by the serine proteinase plasmin $(\mathrm{Pm})$ offers a potential proteolytic system that could be utilized by pathogenic bacteria to gain entry into the host system. Plasminogen (Plg) binding to bacteria can almost be considered a universal event [1-3]. Plasmin has been known to play a significant role in several physiological processes apart from degradation of fibrin clot in fibrinolysis and various extracellular matrix and connective tissue components like 
laminin and fibronectin. Pm also activates procollagenases to active collagenases and is involved in activation of certain prohormones and growth factors [4-6]. Recently, it has also been shown that blood-brain barrier invasion is enhanced by $\mathrm{Pm}$ acquisition [7]. Through activation of matrix metalloproteases (MMPs), Pm can break down extracellular matrices and basement membranes either directly or indirectly and degrade complement and immunoglobulins thereby facilitating the likelihood of bacterial spread (see review $[3])[8,9]$. Therefore, Pm activity must be tightly controlled in order to maintain tissue homeostasis and avoid random tissue damage. Such regulation is achieved by the plasminogen system due to the availability of Plg receptors (PlgRs) and plasminogen activators (PAs).

Bacteria interact with the Plg system by secreting PAs and expressing PlgRs on their surface which direct the Pm activity to locations where proteolytic activity is required. Many of the bacterial PlgRs are critical virulence factors and are among the major targets of vaccine development.

The fibrinolytic system is known to play an important role in the inflammatory response to bacterial infections and host Plg system plays a central role in fibrinolysis. The fibrinolytic system functions to break down the existing fibrin-containing blood clot and is an important constituent of wound-healing mechanisms. Fibrin clots are formed during coagulation and injury to blood vessel walls resulting in fibrin deposition and platelet aggregation. The main active enzyme involved in the fibrinolytic process is Pm. Fibrinolysis is initiated when Plg is converted to Pm by host physiological activators urokinase-type plasminogen activator (uPA) or tissue-type plasminogen activator (tPA). During infection, at the site of local microbial injury, host inflammatory cells in association with bacterial secreted products like endotoxins generate a vigorous response in the surrounding vasculature resulting in local vascular thrombosis. This serves to wall off the site of infection and can, in turn, entrap bacteria and acts as a barrier to prevent bacterial invasion and systemic spread. Most likely this is why fibrin deposits are often seen at the site of infection. The formation of active Pm on the bacterial surface facilitates the degradation of the fibrin layer deposited by the host around the site of local infection promoting release of bacteria from fibrin clot and subsequently assists in ECM degradation thereby facilitating the bacterial dissemination into deeper tissues. Therefore, there is an exquisite mechanistic relationship between the bacterial proteins and host protein which facilitate bacterial dissemination and survival. Through their ability to bind to host Plg directly, PlgRs therefore serve to enhance the activation of surface bound $\mathrm{Plg}$ to $\mathrm{Pm}$, creating a proteolytic microenvironment to be employed by pathogens to catalyze degradation of matrix barriers, which then assists the spread of the bacteria [23, 24] (Figure 1). In recent years, studies to understand the mechanisms and the role of the Plg system in bacterial infections have increased significantly, and this paper summarizes our present knowledge of a select group of bacterial pathogens that utilize host $\mathrm{Plg} / \mathrm{Pm}$ system for the dissemination into surrounding tissue.

\section{Key Players in the Plasminogen System}

2.1. Plasminogen and Plasmin. Human plasminogen (hPlg) is synthesized in the liver as a $90 \mathrm{kDa}, 810$ amino acid polypeptide chain. During secretion, a 19 amino acid leader peptide is cleaved generating the mature form of this protein, which comprises 791 amino acids $[25,26]$. This native form of Plg is called Glu-Plg due to the presence of an aminoterminal glutamic acid residue. The Plg molecule contains a total of seven structural domains, each with different properties. The $\mathrm{N}$-terminal portion of the molecule consists of an activation peptide (AP) followed by a series of 5 repeating homologous triple-disulfide-linked peptide regions, approximately 80 amino acids in length, termed kringles (K1-K5). Cleavage of the peptide bond between residues 77 and 78 is required for the release of the activation peptide. The truncated form of the zymogens is then designated as Lys-Plg. The cleavage of the Arg561-Val562 peptide bond in $\mathrm{hPlg}$ leads to the formation of Pm, which contains a heavy chain of 561 amino acid residues, disulfide linked to a light chain of 230 amino acid residues. The $65-\mathrm{kDa}$ heavy chain comprises the N-terminal portion of the Plg molecule, which consists of AP and 5 kringles (K1-K5) (Figure 2). The function of the five kringles in the heavy chain of $\mathrm{Plg}$ is primarily to mediate protein-protein interactions, such as those between binding of Plg or Pm to fibrin, ECM targets, and lysine-containing receptors/analogues. Plg kringles are also independently involved in angiogenesis and inhibition of cell migration [27, 28]. The Pm light chain contains the carboxyl terminus of $\mathrm{hPlg}$, which comprises the catalytic domain that resembles that of the serine protease family. The catalytic triad of amino acids that define serine proteases is present in human $\mathrm{Pm}$ and consists of His603, Asp646, and Ser741 [5]. The catalytic domain or serine protease domain (SP) of $\mathrm{Pm}$ is a compact module that can recruit adapter molecules, or cofactors, such as the bacterial PAs streptokinase and staphylokinase, which modify the substrate presentation to the enzyme and its specificity [29]. Almost all kringle modules bind to lysine or lysine-like ligands except K3. K1 and K4 exhibit the strongest ligand affinities [30-33] while K2 possesses the weakest affinity [34]. K2 shows strong affinity to a endopolypeptide (VEK-30) derived from Streptococcal Plg receptor M protein (PAM) [35]. The binding strength of kringle modules is dependent on the nature of the ligand.

Glu-Plg can adopt two different conformations, $\mathrm{T}$ and $\mathrm{R}$, which highly influence their activation capability. The $\mathrm{T}$ state (tight conformation) is a compact state seen in full-length hPlg. In this conformational state, $\mathrm{Plg}$ is poorly activated [36, 37]. Investigations of recombinant (r) Glu$\mathrm{Plg}$ variants have shown that both negative and positive effector molecules have an influence on the structure and activation of $\mathrm{Plg}[38,39]$. For example, it has been suggested that in the presence of $\mathrm{Cl}^{-}$, Lys side chains, and/or pseudoLys arrangements in the 77 amino acid NH2-terminal AP interact with $\omega$-amino acid binding sites of K1Plg, K4Plg, and to a lesser extent, K5Plg. In addition, studies have shown that a number of activation peptide residues interact with these kringle sites and participate in the stabilization of the 


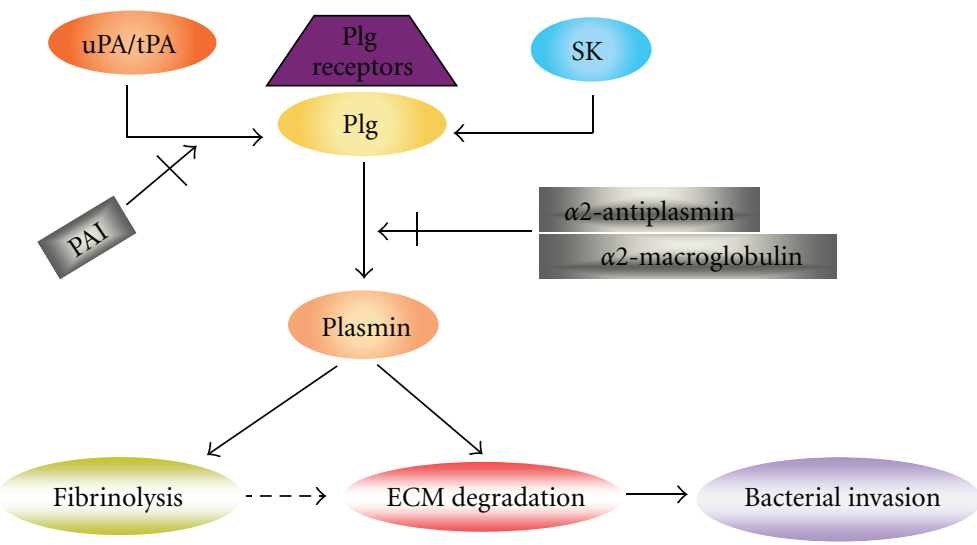

Figure 1: Simplified overview of the mammalian plasminogen system and its utilization by bacteria. Bacterial plasminogen receptors immobilize plasminogen on the surface, which enhances activation of plasminogen to the active serine protease, plasmin, by host plasminogen activators uPA, tPA and/or bacterial plasminogen activators like streptokinase (SK). Both tPA and uPA can be inhibited by plasminogen activator inhibitors (PAI), while plasmin activity is controlled by its major inhibitor, $\alpha 2$-antiplasmin, and to a lesser extent by $\alpha 2$-macroglobulin. Plasmin degrades fibrin clot (fibrinolysis) and various ECM components which enables bacterial migration through tissue barriers.

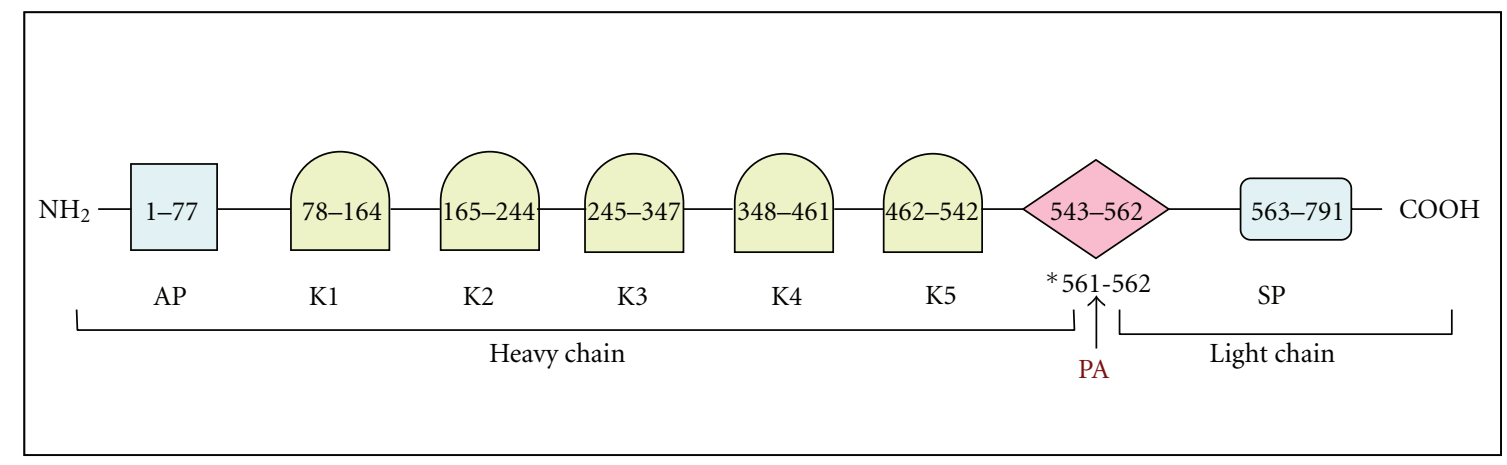

FIGURE 2: Schematic presentation of the structure of human Plg. From the amino terminus of the mature protein, the 77-residue activation peptide (AP) is followed by 5 kringle domains (K1-K5) containing lysine binding sites and the catalytic SP domain. R561-V562, which is proteolytically cleaved to generate Pm, is shown with an asterisk. The cleavage site for plasminogen activator (PA) is shown by an arrow. Heavy chain and light chains after proteolytic cleavage are marked with lines.

T conformation [40]. On the other hand, the conformation of Glu-Plg changes to a more flexible relaxed state ( $\mathrm{R}$ state), that is readily activated when the activation peptide (AP) is displaced from its kringle binding sites upon addition of $\omega$-amino acids, for example, $\mathcal{E}$-aminocaproic acid (EACA). Once Glu-Pm is formed, it acts as a catalyst for cleavage of the AP from Glu-Plg and Glu-Pm, thus catalyzing conversion of Glu-Plg to Lys78-Plg or Glu-Pm to Lys78-Pm. Release of the AP renders Lys78-Plg a more activatable substrate due to its transformation to the $\mathrm{R}$ state and transition to a protein that is now insensitive to negative and positive effector molecules $[41,42]$. The Lys-Plg conformation enables it to interact with PlgRs and also facilitates ready conversion to Pm on the cell surface [43].

The atomic structures of the kringles as well as a truncated form consisting of a 20 amino acid long fragment of the heavy chain connected to the light chain by two disulfide bridges have been reported [44-47]. The structural changes that the catalytic domain undergoes in association with the activation of Plg have also been identified by crystallography [48].

Recently, the crystal structure of full-length type II human Plg has been solved [49]. The structure shows a closed conformation which reveals that $\mathrm{N}$-terminal AP domain makes extensive contacts with $\mathrm{K} 4$ and $\mathrm{K} 5$. These interactions, together with SP domain and chloride ions, maintain the $\mathrm{T}$ conformation. The Arg561-Val562 peptide bond which is proteolytically cleaved to convert Plg to $\mathrm{Pm}$ is shielded by the position of $\mathrm{K} 3 / \mathrm{K} 4$ linker which perhaps protects the proenzyme from unwanted activation in the closed state. Position of K3 might also serve as a physical barrier to activating proteases. However, superpositioning SK, which can readily activate the closed state of plasminogen, to the Plg structure revealed that despite these safeguards SK can bind to the SP domain in a way that can cleverly avoid the kringle modules. K3 forms a significant interface (including a disulphide bond) with $\mathrm{K} 2$, as previously observed in the structure of angiostatin [50]. These interactions position 
K3 next to the SP domain. The authors also noted that differences in glycosylation most likely alter the position of K3. The structure shows that LBS of K1 is exposed and most likely mediates proenzyme recruitment to fibrin or receptors. Previously it was suggested from the structures of isolated kringle domains in the presence or absence of lysine analogs that $\mathrm{K} 1$ is most likely not involved in structural rearrangement but another kringle(s) might be. Further analysis of the Plg structure reveals that indeed K5 is the kringle crucial for triggering Plg conformational change and peeling away of K5 from AP domain may initiate that change. Another human plasminogen closed conformation structure published recently also supports these observations and shows that only K1-LBS is readily available for ligand and/or receptor binding while LBS of other kringles, except $\mathrm{K} 1$, are involved in intramolecular interactions [51].

2.2. Host Plasminogen Activators. Plasminogen is present in large amount in blood as well as in tissues. Due to the broad biological significance of Plg and Pm in cellular processes, it is therefore of utmost importance that this enormous reservoir of proteolytic activity be tightly regulated. This is achieved by specific PAs, inhibitors, and receptors in order to restrict the generation of $\mathrm{Pm}$, as well as immobilize Plg to its receptors or target molecules.

Mammals have two PAs, tissue-type plasminogen activator (tPA) and urokinase-type plasminogen activator (uPA) which were originally identified in tissue and urine extracts, respectively [52]. They recognize and cleave the R560-V561 peptide bond in Plg generating active Pm. uPA has been identified as a critical trigger for Pm generation during cell migration and invasion, under physiological and pathological conditions and, therefore, appears to be the primary PA in eukaryotic cell migration processes, whereas tPA is the main $\mathrm{PA}$ in fibrinolysis and maintenance of vascular patency [4]. The activities of PAs are regulated by specific plasminogen activator inhibitors (PAIs) thereby restricting the generation of Pm for extracellular matrix (ECM) as well as intravascular fibrin degradation $[53,54]$.

Both PAs are serine proteases that are secreted as lowactivity single-chain zymogens and proteolytically processed by plasmin into fully active two-chain molecules held together by a single disulfide bond [52, 55, 56]. Crystal structures of the catalytic domains of tPA and uPA have shown that the active sites are located in the $B$ chain in both PAs and Plg specificity is determined by the insertion loops which are positioned around the active site cleft $[57,58]$. In uPA, the A chain consists of one kringle structure and a growth factor-like domain, which contains the receptorbinding amino acid sequence [59]. In tPA, the N-terminal region contains a "fibronectin-type II" finger domain, an "EGF-like" domain and two "kringle" domains. The fingerlike domain, together with the second kringle domain, provides tPA with high affinity for fibrin [60]. A large serine protease catalytic domain is located at the carboxyl terminus, similar to uPA.
2.2.1. Urokinase-Type Plasminogen Activator (uPA). uPA is expressed in a variety of tissues as a 411 amino acid glycoprotein with an apparent molecular weight of $53 \mathrm{kDa}$. uPA-mediated Pm generation results in the proteolytic activation of matrix metalloproteinases (MMP), other ECM proteinases, and growth factors. Therefore, uPA initiates a proteolytic cascade that leads to degradation of the ECM, facilitating processes such as cell attachment and detachment, tissue remodeling, and tumor metastasis. uPA binds to a specific glycoprotein receptor (uPAR) which increases its overall catalytic efficiency $[61,62]$. UPAR restricts uPA activity to the cell surface, where Plg is also bound to its cognate sites [63]. Plg and PAs are thus colocalized on cells and tissues thereby reinforcing cell-associated proteolysis. uPA/uPAR interactions account for localized pericellular proteolysis, as opposed to the extracellular and plasma proteolytic activity of tPA. Alternatively, uPA-uPAR binding induces a conformational change in the complex, which initiates signal transduction cascades that affect cell proliferation and survival, cytoskeleton dynamics, and cell adhesion [64].

2.2.2. Tissue-Type Plasminogen Activator (tPA). tPA, a 530 amino acid glycoprotein is primarily secreted by vascular endothelial cells as a prozymogen with very low level activity until proteolytically activated by Pm [65]. A variety of stimuli, such as thrombin, histamine, bradykinin, adrenaline, acetylcholine, and shear stress can govern the release of tPA. The major role of tPA is to degrade fibrin in blood vessels. tPA activity is greatly stimulated by fibrin which interacts with kringle 2 and the finger and EGF-like domains [66]. Accordingly, tPA synthesis is induced under ischemic conditions. In $\mathrm{tPA}-$ deficient $\left(\mathrm{tPA}^{-/-}\right)$mice, clot lysis is strongly impaired whereas, in uPA-deficient mice, there is occasional fibrin deposition [67]. In addition to its role in fibrinolysis, tPA has been shown to have an additional role that is unrelated to its proteolytic activity and independent of Pm generation. tPA can act as a ligand to cell surface proteins and trigger several cellular responses $[68,69]$. In $\mathrm{tPA}^{-/-}$mice, cerebellar granule neurons migrate significantly slower than granule neurons from wild-type mice; as a consequence, late arriving neurons are impaired in their synaptic interactions [70].

Annexin 2 has been identified as a plasma membrane receptors for tPA in endothelial cells which also possess binding affinity for Plg but not uPA [71-73]. Annexin 2 is a highly conserved member of the annexin super family of calcium-dependent, phospholipid-binding proteins [74]. Like all annexin family members, annexin 2 has a variable N-terminal "tail" and a conserved C-terminal "core" region. Annexin 2 heterotetramer consists of two annexin 2 monomers dynamically linked by two molecules of p11 (also known as S100A10), a member of the S100 family of calciumbinding proteins. Binding of p11 to annexin 2 is essentially irreversible. This heterotetrameric complex which is the predominant species in most cells is referred to as AIIt and provides a surface for tPA and plasminogen interaction and may even have a greater stimulatory effects on tPA-dependent plasmin generation $[75,76]$. Both plasminogen and tPA bind 
to distinct annexin 2 domains. As discussed earlier, binding of plasminogen to its cellular receptor is dependent on the interaction of plasminogen with the carboxyl-terminal lysines of the receptor. In a purified-protein system, native human placental annexin 2 conferred an approximately 60 fold increase in catalytic efficiency of tPA-dependent $\mathrm{Plg}$ activation which is almost completely negated in the presence of Lys analogues indicating a lysine-dependent interaction [75]. As annexin 2 lacks carboxyl-terminal lysine, it has been proposed that proteolytic processing of annexin 2 at a specific site might expose a carboxyl-terminal lysine, specifically Lys 307 which could mediate annexin 2 binding to Plg [73]. However, this has never been demonstrated either in vitro or in vivo. Mutational study of this lysine did not dramatically alter the stimulatory activity of annexin 2 when compared with the wild-type recombinant annexin 2 [75]. On the other hand, p11 subunit of AIIt has the prerequisite carboxyl-terminal lysines, mutation of which resulted in reduced tPA-dependent Plg activation compared to wildtype p11 subunit [75]. These results suggest that carboxylterminal lysine residues of p11 mediate Plg binding and it is probably these lysines which result in the stimulation of tPA-dependent Plg activation of AIIt (reviewed in [77]). P11 subunit binds to the aminoterminal side of annexin 2. It is also the aminoterminal in particular Leu-Cys-Lys-Leu-SerLeu hexapeptide within the aminoterminal "tail" domain which mediates tPA binding and $\mathrm{Cys}^{8}$ of this sequence has been proposed to be essential for the binding [78]. Several studies also suggest a physiological role for annexin 2 in fibrin homeostasis. Annexin 2 and p11 are not only involved in regulation of plasmin generation, fibrin homeostasis, and angiogenesis but are also involved in tumor growth, invasion, and metastasis (reviewed in [79]) [80]. Annexin 2 and p11 could therefore play the role of physiological receptors of plasminogen.

Low-density lipoprotein receptor-related protein (LRP) is a large two-chain scavenger receptor that mediates clearance of tPA-PAI-1 complex, in vitro $[81,82]$. Both growth factor and the finger domain of tPA are required for this interaction. LRP binds a variety of biologically diverse ligands including the broad spectrum protease inhibitor $\alpha 2$ macroglobulin $(\alpha 2 \mathrm{M})$ and free and PAI-complexed plasminogen activators [83]. LRP sequesters proteases and/or protease-inhibitor complexes and thereby regulates extracellular proteolysis thus decreasing the overall protease load in the pericellular space $[84,85]$.

Apart from uPA and tPA, certain proteases belonging to coagulation cascade have also been shown to activate Plg directly. These accessory activators include kallikrein, factor XIa and factor XIIa $[86,87]$. Type IV collagen is also known to immobilize Plg and lead to enhanced tPA-mediated Plg activation [88]. Factor VII-activating protease has also been reported to be a potent in vitro activator of single-chain Plg activators, but its physiological role is not yet clear [89]. Plasma protein histidine-proline-rich glycoprotein (HPRG) also contains carboxyl-terminal lysines and is known to bind $\operatorname{Plg}[90,91]$.
2.3. Plasmin and Plasminogen Activator Inhibitors. The activation of Plg is negatively modulated by a family of serine protease inhibitors known as serpins [92]. The mode of action of serpin requires formation of a stable complex with active site serine of the target protease, followed by the proteolytic cleavage of the serpin by target protease [93].

The chief serpin PA inhibitors are plasminogen activator inhibitor-1, -2, -3 (PAI-1, PAI-2 and PAI-3) and a broadspectrum protease inhibitor nexin [94]. PAI-3 can inhibit both uPA and tPA albeit with a much slower rate than PAI1 and -2 [56]. Out of the two major PAIs, PAI-1 is the most ubiquitous and most rapidly acting physiological inhibitor of both uPA and tPA. PAI-2, on the other hand, is less effective towards single-chain tPA and does not inhibit single-chain uPA but can inhibit both two-chain uPA and two-chain tPA with comparable efficiency.

The chief physiological inhibitor of plasmin is the serpin $\alpha 2$-antiplasmin. This glycoprotein forms a complex with plasmin by binding to kringle 1-3 of plasmin [95]. Since the same lysine-binding kringle sites mediate Plg binding to receptors, receptor-bound plasmin(ogen) is resistant to inhibition by $\alpha 2$-antiplasmin. Another broad-spectrum proteinase inhibitor $\alpha 2$-macroglobulin can also inhibit plasmin. This nonserpin forms a noncovalent complex with plasmin; however, this inhibition takes place only when there is significant decrease in the local or systemic concentration of $\alpha 2$-antiplasmin [96].

\section{Bacterial Plasminogen Activators}

Several pathogenic bacteria, such as Streptococcus and Staphylococcus, also produce PAs that are either secreted or surface-bound proteins. Streptokinase (SK) and staphylokinase (SAK) are not enzymes in and of themselves but form 1:1 complexes with Plg and Pm, leading to changes in conformation and specificity of Plg. Crystal structures of SK and SAK reveal that they have similar structural fold, although sequence homology is relatively low $[97,98]$. The mechanism of Plg activation by SK and SAK is similar but differs in some respects. While SK-Plg is enzymatically active, SAK-Plg is inactive and requires the conversion of Plg to Pm. Another important difference is that SAK primarily activates fibrin-bound Plg. This requirement has encouraged studies with SAK regarding its ability to function as an in vivo thrombolytic agent [99].

\subsection{Activation of Human Plasminogen by Streptokinase.} Invasive bacterial infections caused by Streptococci represent one of the most extensively studied models for interactions between pathogens and the Plg system [100]. Streptococci have the ability to invade nonphagocytic cells by breaking the host cellular and tissue barriers through interaction with host proteins that facilitate access into the vascular system [101, 102]. Interactions between the Plg system and streptokinase (SK) have been hypothesized to promote the bacterial invasion into tissues [103]. The SK, secreted by $\beta$-hemolytic group $\mathrm{A}, \mathrm{C}$, and $\mathrm{G}$ streptococci, is the prototypical bacterial plasminogen activator. It is a 440 
amino acid protein containing $\alpha, \beta$, and $\gamma$ domains, with a 26 amino acid N-terminal signal peptide that is cleaved during secretion to yield a 414 amino acid mature protein [104]. Experiments have demonstrated that each individual domain can bind to Plg. However, they cannot activate Plg independently. Mutagenesis studies have shown that the $\alpha$, $\beta$, and $\gamma$ domains cooperatively induce the formation of an active site within the hPlg activator complex, providing a means for the substrate Plg to be recognized by the activator complex, mainly through interactions mediated by the SK $\alpha$ domain $[105,106]$. Interestingly, unlike other Plg activators which activate Plg by limited proteolysis, SK lacks hydrolytic activity. Thus, in order to activate Plg, SK has to bind to Plg and induce within it an active site through nonproteolytic mechanisms.

The activation of Plg by SK involves two major mechanistic steps: (1) formation of a PA complex and (2) the activation of substrate Plg. The crystal structure of SK from $S$. pyogenes in complex with the catalytic unit of Plg shows that the formation of the activator complex involves interactions between the carboxyl-terminal domain of SK and the catalytic domain of Plg [97]. In the SK-Plg complex, the active site of Plg is exposed and functions without hydrolysis of the Arg560-Val561 peptide bond [107]. Crystallographic studies have also determined the surface area of the respective SK domains available to interact with $\mathrm{Plg}$ and found that the interaction sites are located in the loops of $\alpha$ and the $\gamma$ domains of the SK. In the second step of the activation, SK-Plg complexes become catalytic activators of the remaining Plg. The formation of the complex induces conformational changes, such that Plg is converted to Pm [108]. The Plg activation mechanism is also modulated by lysine-binding site- (LBS-) dependent interactions between SK and the kringle domains of Plg and Pm [109-111] which most likely involves $\mathrm{K} 5$ of $\mathrm{Plg}$ and $\beta$ and/or $\beta, \gamma$ domains of SK $[105,112]$.

Although the specific roles of the domains of SK that function in various ways in the activator complex have been revealed $[113,114]$, the basis for the species selectivity of SK in activation of mammalian Plg is still unclear $[115,116]$. Human and nonhuman-derived SKs differ from each other and activate Plg in a species-specific manner. Early studies with rabbit Plg showed weak activation when incubated with SK produced by a strain of human origin. It was found that although a complex was formed between SK and rabbit Plg, SK was rapidly degraded to inactive forms, indicating that the complex was unstable [117]. Investigations with SKs isolated from streptococcal strains from equine or porcine origin have shown that although equine/porcine-derived SKs interact with hPlg, no activation was achieved. A similar situation was observed when either equine or porcine Plg was incubated with SK from a bacterial strain of human origin. Comparisons of amino acid sequences of different mammalian-derived SKs have shown that there is low sequence homology. These data indicated that the complex formed between SK and Plg could vary in primary structure and conformational properties, affecting Plg activation [118]. This remarkable species specificity is believed to originate from the species-specific interaction between SK and the preferred host's Plg. Using transgenic mice expressing human Plg it has been shown that a marked increase in the susceptibility of mice to group A streptococcus (GAS) was observed which is largely abrogated by deletion of the SK gene. These results demonstrate that SK is a key determinant for host specificity of streptococcal infection [119].

3.2. Activation of $h P g$ by Staphylokinase. Staphylokinase (SAK) is a 136 amino acid protein produced by strains of S. aureus. SAK does not possess protease activity by itself. Instead, hPlg activation by SAK depends on the formation of a stoichiometric complex between SAK and Pm. The SAK$\mathrm{Pm}$ is formed from SAK-hPlg in the presence of other PAs for example, tPA [120]. The SAK-Pm complex modifies SAK within the complex by cleavage of the Lys10-Lys11 peptide bond and subsequently converts SAK-Plg to SAK-Pm, which in turn converts free Plg to Pm. The kringle domains of Plg are not involved in the interaction with SAK, and there is evidence that Arg719 in Plg and Met26 in SAK are important for the binding $[98,121]$. Moreover the $\mathrm{NH}_{2}$-terminal region of SAK is important for active site formation in the Pm molecule in the binary complex $[99,121,122]$.

Plg activation mediated by SAK differs from SKmediated Plg activation in some major aspects. (i) The SAK-Plg complex is enzymatically inactive and requires conversion of Plg to plasmin. (ii) SAK requires fibrin as a cofactor. (iii) Active SAK-plasmin complex is efficiently inhibited by $\alpha_{2}$-antiplasmin. However, binding of Plg to fibrin or bacterial cell surfaces protects against inactivation by $\alpha_{2}$-antiplasmin and, more importantly, enhances the SAKinduced Plg activation [123]. (iv) Binding of $\alpha_{2}$-antiplasmin to the SAK-plasmin complex releases SAK from the complex allowing it to interact with other plasmin(ogen) molecules $[121,124,125]$. SAK also binds much more efficiently to substrate-bound Plg than to soluble Plg [126]. Other than $\mathrm{Plg}$ activation, SAK can also induce immunogenic antibody responses and proliferation of SAK-specific T lymphocytes [127]. Furthermore, SAK can directly interact with the host innate immune system and inhibit the bactericidal effect of $\alpha$-defensins, thereby reducing the rate of Plg activation. As a result, the functional activity of SAK promotes the bacterial infection process [128]. The observation that SAK primarily activates Plg bound to fibrin without causing systemic Plg activation has raised interest in the clinical use of SAK as a thrombolytic agent to dissolve the fibrin component of blood clots [99].

\section{Bacterial Plasminogen Receptors}

Plasminogen activator production is not universal amongst pathogenic bacteria but many bacteria express PlgRs on their surface [1, 129]. Bacterial PlgRs capture Plg on the bacterial surface which in turn enhances its activation to Pm by SK or host plasminogen activators uPA or tPA [130]. Consequently bacteria become proteolytic organisms using the hostderived system and thus facilitate bacterial penetration of endothelial cell layers and degradation of extracellular matrix 
TABLE 1: Bacterial plasminogen receptors.

\begin{tabular}{|c|c|c|c|}
\hline Receptor & Primary bacteria & Possible physiological function & Reference \\
\hline Enolase/SEN & Streptococcus & $\begin{array}{l}\text { Plg binding and uPA/tPA-mediated activation } \\
\text { Fibrinolysis, subsequent extracellular matrix } \\
\text { degradation, and transmigration. Involved in } \\
\text { tumorigenesis, cancer proliferation, invasion, specific } \\
\text { humoral and cellular immune response, myogenesis as } \\
\text { well as hypoxic stress response }\end{array}$ & {$[10]$} \\
\hline GAPDH/SDH/Plr & Streptococcus & $\begin{array}{l}\text { Plg binding and activation by uPA/tPA. Adhesion to } \\
\text { uPAR, fibronectin }\end{array}$ & {$[11,12]$} \\
\hline $\mathrm{M}$ proteins, $\mathrm{PAM}$ & Streptococcus & $\begin{array}{l}\text { Major virulence factor, promote fibrinolysis, } \\
\text { antiphagocytosis, vascular leakage and tissue injury, } \\
\text { proinflammatory properties, adhesion to host cell and } \\
\text { tissues, transmigration and deep tissue invasion, } \\
\text { immunoglobulin binding, acute rheumatic fever }\end{array}$ & {$[13,14]$} \\
\hline OspA, OspC & Borrelia & $\begin{array}{l}\text { Plg activation by host uPA, increased MMP expression, } \\
\text { degradation of soluble and insoluble ECM components, } \\
\text { endothelial monolayer penetration including } \\
\text { blood-brain barrier, effective dissemination in host }\end{array}$ & {$[15-17]$} \\
\hline HP-NAP & Helicobacter pylori & $\begin{array}{l}\text { Fibrin clot stabilization, inhibition of fibrinolysis, } \\
\text { possibly antiphagocytic, tissue factor synthesis and } \\
\text { PAI2 stimulation }\end{array}$ & {$[18]$} \\
\hline $\mathrm{PgbA} / \mathrm{PgbB}$ & Helicobacter pylori & $\begin{array}{l}\text { Lysine-dependent Plg binding, tPA-mediated Plg } \\
\text { activation }\end{array}$ & {$[19]$} \\
\hline DnaK & $\begin{array}{l}\text { Bifidobacterium animalis } \\
\text { subsp. lactis }\end{array}$ & Plg binding; upregulated in response to bile salts & {$[20]$} \\
\hline Flagella & Escherichia coli & Plg binding and activation by host PAs & {$[21]$} \\
\hline Fimbriae & Escherichia coli Salmonella & $\begin{array}{l}\text { Fibronectin binding, adhesion to ECM } \\
\text { components/BM, facilitate penetration }\end{array}$ & {$[22]$} \\
\hline
\end{tabular}

components. Additionally, immobilization of $\mathrm{Pm}$ protects it against the serine protease inhibitor $\alpha_{2}$-antiplasmin [131]. Several bacterial PlgR molecules have been identified and characterized (Table 1). Most of the identified bacterial PlgRs have other important functions as well. In this paper we will focus only on the well-known and well-characterized bacterial PlgRs.

The best characterized PlgRs have been identified in group A and C streptococci from humans. These include $\alpha$ enolase (SEN) [10] and glyceraldehyde-3-phosphate dehydrogenase (GAPDH; also known as SDH and Plr) [11, 12] as well as the streptococcal M-like protein (PAM) [13, 14]. Both GAPDH and enolase are glycolytic enzymes expressed on the bacterial surface $[132,133]$. These are anchorless multifunctional proteins which, in addition to their housekeeping functions, are also involved in bacterialinduced fibrinolysis and inflammation through their ability to bind Plg.

Other than streptococci, GAPDH is also expressed on the surface of several Gram-positive bacteria including pneumococci as well as pathogenic Escherichia coli (E. coli) and binds to plasminogen, fibrinogen, and fibronectin binding proteins [133-135]. Enterohemorrhagic and enteropathogenic E. coli are reported to secret GAPDH which was found to bind human Plg and fibrinogen therefore suggesting a possible role in bacterial pathogenesis [135]. GAPDH (also known as streptococcal surface dehydrogenase-SDH) possesses lower affinity for Glu-Plg than Pm [133]. The C-terminal lysine residue of GAPDH appears to be essential for Pm binding as substitution of this residue with leucine abolishes binding. However, this replacement failed to show any effect on Plg binding indicating possible involvement of other streptococcal PlgRs [136]. It was found to be impossible to analyse the effect of GAPDH deletion on Pm binding since GAPDH appears to be essential for viability in GAS. However, analysis of swine pathogen Streptococcus suis mutant lacking cell surface GAPDH activity showed reduced Pm affinity. Lysinedependent Plg binding by recombinant GAPDH isoform at physiological concentrations has been recorded for Bacillus anthracis [137]. Immunization of mice with this isoform offered significant protection against Bacillus anthracis infection. Taken together, these data establish the significance of GAPDH as a Plg receptor but also indicate that GAS probably expresses multiple PlgRs. In addition to its $\mathrm{Plg}$ binding activity, the GAPDH/SDH binds to the ectodomain D1 of uPAR/CD87 on Detroit human pharyngeal cells and mediates bacterial adherence to host cells [138]. SDH has also been shown to be involved in the regulation of phosphorylation of human pharyngeal cells which suggests a role for this enzyme in signal transduction and cell-tocell signalling between streptococci and pharyngeal cells [139, 140]. GAPDH may also act as a virulence factor which could contribute to pathogenesis [135].

Like GAPDH, enolase is a glycolytic enzyme identified in archaebacteria to mammals. It is a highly conserved protein with similar overall fold and identical catalytic residues in 
all organisms [141]. There are three isoforms of enolase$\alpha, \beta$, and $\gamma$ which share high sequence identity. Of these, $\alpha$ enolase is present in almost all tissues [142-144]. Enolase consists of a relatively small $\mathrm{N}$-terminal domain and a rather large C-terminal domain. In some eubacteria, for example, streptococci, $\alpha$-enolase is octameric [145], whereas in eukaryotes, enzymatically active enolase is present as an antiparallel dimer [146]. Enolase is a ubiquitous surfaceassociated protein although it is not clear how enolase is exported to the surface because it lacks the N-terminal signal peptide required for surface export as well as the membrane anchorage motif required for cell wall anchorage $[10,132,145,147]$. Enolase is a multifunctional protein which, apart from being a key player in metabolism, is also involved in tumorigenesis, cancer proliferation, invasion, specific humoral and cellular immune response, and myogenesis, as well as hypoxic stress response (reviewed in [144, 148, 149]). Interestingly, surface-associated enolase serves another important function in both pro- and eukaryotes in that it acts as a PlgR by binding to and activating host Plg [132, 150-155] on cell surfaces and thereby facilitating fibrinolysis and subsequent extracellular matrix remodelling. This may in turn assist in bacterial invasion of host cells. Binding leads to activation of Plg to Pm by the action of tPA or uPA [156, 157]. Enolase binds to kringles of Plg in a lysine-dependent manner. C-terminal lysine residues are critical for binding to $\mathrm{Plg}$ as the lysine analog $\mathcal{E}$ aminocaproic acid significantly inhibits binding as has been shown in Borrelia and human pharyngeal cells [158, 159]. However, ionic interaction does not affect this binding [158]. Lysine residues at positions 420 and 427 of enolase were found crucial in Plg-binding activity in Aeromonas hydrophila SSU [160]. It was also found that immunization of mice with purified recombinant enolase significantly protected the animals against a lethal challenge dose of wild type (WT) A. hydrophila suggesting that enolase could potentially be important for the viability of the pathogen [160]. Similar to GAPDH, $\alpha$-enolase shows greater affinity for Lys-Plg than to Glu-Plg [161]. Lys-Plg-coated GAS resulted in increased adherence of GAS to human pharyngeal cells (Detroit 562) that have $\alpha$-enolase expressed on their surface [159]. Additionally, in pneumococcal enolase, a nineresidue motif [FYDKERKVY] has been found to be the key cofactor for Plg binding and degradation of ECM proteins as well as important for dissolution of fibrin or laminin and transmigration of pneumococci through fibrin matrices [162]. Using an intranasal mouse infection model it has been shown that the functional inactivation of the nine-residue motif significantly impairs virulence of streptococci [163]. This motif has been found to be pivotal in other pathogens as well $[144,160]$. However, the full conservation of the motif does not seem to be necessary for Plg activation [164]. Interestingly, pretreatment of mice with recombinant enolase from Streptococcus sobrinus suppressed the primary immune response against $\mathrm{T}$-cell dependent antigens and also induced an early production of the anti-inflammatory cytokine, interleukin-10, thereby suggesting that surface enolase might act as an immunosuppressive agent [165]. Because of its location and possible function, enolase therefore has the potential of being a therapeutic target $[149,166]$.

Perhaps the best characterized bacterial PlgRs are $M$ proteins secreted by group A streptococcus (GAS). GAS is a highly specific human pathogen. Its efficient colonization and dissemination in the host lead to a broad spectrum of diseases that range from simple and uncomplicated pharyngitis, tonsillitis, and skin infections, for example, impetigo, to life-threatening invasive illnesses including pneumonia, bacteremia, necrotizing fasciitis, streptococcal toxic shock syndrome, as well as nonsuppurative complications like acute rheumatic fever, and glomerulonephritis [167]. GAS produces a variety of surface-bound and secreted virulence factors which are known to contribute to the severity of their infections [168]. Among these, M- and M-like protein PAM (plasminogen binding M-like protein), which are anchored to the cell wall, play key roles in bacterial resistance to phagocytosis, adherence, invasion, and microcolony formation in tonsillar tissue (reviewed in [168]). $M$ and M-like proteins function through various mechanisms for effective dispersion of the bacteria in the host. M proteins enable GAS to resist host immunity and invade the host by binding to IgG and IgA, as well as other proteins of the innate immune system. Apart from its role as antiphagocytic, $\mathrm{M}$ and $\mathrm{M}$-like proteins also interact with and stimulate activation of the host fibrinolytic system [119]. M and M-like proteins of GAS are able to bind to host Plg directly $[13,35]$ or indirectly via fibrinogen $(\mathrm{Fg})$ and/or fibrin $(\mathrm{Fn})[169,170]$ and serve to enhance the activation of Plg to $\mathrm{Pm}$. M proteins have been studied extensively since their discovery in 1928 and are now amongst the best studied virulence factors of pathogenic bacteria [167, 171]. M proteins exhibit extensive sequence variations between strains accounting for over 130 distinct serotypes, each one exhibiting unique antigenic properties [172]. This enormous diversity of GAS serotypes is a major obstacle in the development of vaccines against GAS.

$M$ proteins adopt a dimeric $\alpha$-helical coiled-coil structure [173] tethered to the membrane at their C-terminal end. The hypervariable $\mathrm{N}$-terminal region, which extends into the external environment, varies extensively in sequence between different bacterial strains and gives rise to the socalled antigenic variation in $\mathrm{M}$ proteins. $\mathrm{M}$ proteins consist of several domains of distinct functionality. The first 40 residues, which form the signal sequence, are absent in the mature protein. Mature PAM proteins begin with a variable $\mathrm{P}$ domain that contains two 13 amino acid repeats termed a1 and $\mathrm{a} 2$. This is followed by three $\mathrm{C}$ repeats and a $\mathrm{D}$ domain all of which are highly conserved across the M-protein family. These sequences bind a variety of human plasma proteins including members of the complement system. The highly conserved Pro/Gly domain is inserted in the GAS cell wall and anchors PAM on the bacterial surface. PAM binds to the kringle 2 (K2) domain of hPlg via its ala2 domain $[13,174]$ whereas M proteins on other GAS strains bind to Fg through $B$ repeats, which in turn interacts with Plg via K1, K4, and/or K5 domains of Plg $[170,175]$. Binding of PAM to hK2/hPlg is mediated mostly by $\mathrm{R} 72, \mathrm{H} 73, \mathrm{E} 75, \mathrm{R} 85$, and $\mathrm{H} 86$ residues in the a1/a2 repeat of native PAM. Substitution of the central lysine in the al repeat sequence DAELQRLKNERHE reduced 
Plg binding by $80 \%$ [14]. The role of the a1 and a 2 regions in Plg binding was further demonstrated by expressing the a1 and the combined ala2 regions as chimera to Arp4, an M-like protein which lacks Plg binding. Not only did the recombinant chimeric Arp/PAM proteins bind to Plg and Pm but also the expression of these fusion proteins conferred Plg binding on the streptococcal host strains lacking the Plg-binding ability [171]. In the presence of Plg, the a1Arp4 fusion in an SK-producing strain resulted in surfaceassociated plasmin activity, whereas a host strain with an inactivated SK gene required exogenous SK for Plg activation [142].

PAM is encoded by the emm53 gene, which is associated with the GAS strains that cause skin infections in humans $[176,177]$. Inactivation of emm53 leads to a loss of Plg binding in vitro and attenuated infection in an experimental model of impetigo as well as in transgenic mice expressing human Plg. The surface-bound Plg can be activated by SK or host PAs. In this way, PAM concentrates Plg on the surface of the bacteria and greatly augments the SKmediated conversion of $\mathrm{hPlg}$ to $\mathrm{hPm}$. PAM appears to work synergistically with SK to yield bacteria-bound $\mathrm{Pm}$ in vivo.

\section{Mechanisms of Pathogen Invasion Using Host and Bacterial Proteins}

5.1. Interaction of Bacteria with the Fibrinolytic Cascade via Plasminogen Receptors. The connection between microbial infection and fibrinolytic system has been known since 1933 when haemolytic streptococci from human infection samples were found to possess fibrinolytic activity [178]. Speculation was rife when it was reported that injection of streptococcal cell wall products triggered activation of the coagulation pathway in rats [179]. The binding of bacterial Plg receptors to Fg has been extensively studied mostly in GAS [180]. Plasminogen deficient $\left(\mathrm{Plg}^{-/}\right)$mice have been utilized in several pathogen challenge models. Binding of host Fg to M proteins of GAS enhances SK function in plasma. Using a mouse skin infection model it has been shown that GAS isolates with a surface-bound SK-human Plg-human Fg complex are invasive when injected into the skin of wild-type (WT) mice but not $\mathrm{Plg}^{-1-}$ mice [24]. This also demonstrates that $\mathrm{PlgR}$ interaction with host Plg facilitates bacterial invasion. This supports the in vitro observation that GAS incubated with human plasma acquires Pm activity on its surface [181]. In subcutaneously infected mice, coadministration of human $\mathrm{Plg}$ considerably increased the susceptibility to GAS infection which was largely abolished by inactivation of the SK gene [103]. Similarly, inactivation of SK gene leads to a loss of virulence in a human-skin-mouse model for impetigo [182]. In an epidemiological study, GAS strains expressing M proteins isolated from invasive infectious cases were found to bind more $\mathrm{Plg}$ than strains isolated from noninvasive infectious cases in the presence of Fg and SK [183]. These results demonstrate the importance of bacterial Plg receptors in host pathogen interaction and indicate that SK and PlgRs probably share a synergistic action. A transgenic line of mice that express only human Plg has been generated to study the role of the host fibrinolytic system in GAS infection [119]. These mice showed increased mortality and increased bacterial dissemination, when subcutaneously infected with GAS. The presence of M protein was found to be required for full scale virulence. In this infection model it was also demonstrated that decreasing Fg levels facilitated bacterial spread thereby suggesting that in the absence of Pm activity, fibrin clot formation can be an effective host-defense mechanism. Fibrin-mediated protection to infection-stimulated hemorrhage has also been documented in mice infected with Toxoplasma gondii [184]. In an infection study using $\mathrm{Plg}^{-/-}$mice and mice deficient in Plg activators, it was observed that during infection with Mycobacterium avium the liver granulomas in $\mathrm{Plg}^{-/-}$mice had enhanced fibrin and fibronectin deposition, as well as increased neutrophil infiltration suggesting that $\mathrm{Pm}$ plays a role in the turnover of extracellular matrix proteins within granulomas, likely limiting the fibrotic response in these lesions [185].

The binding of $\mathrm{Fg}$ to $\mathrm{M}$ protein may also play a role in modulating bacterial-phagocyte interaction. Fg-M protein complex inhibits complement deposition on the bacterial surface thereby protecting GAS from phagocytosis [169]. M protein-Fg complex can bind to $\beta 2$ integrins, thus activating neutrophils and consequently inducing vascular leakage that could cause extensive pulmonary damage [186]. This further establishes the importance of Fg in pathophysiology of streptococcal infection. $\mathrm{M}$ protein-Fg interaction and subsequent activation of coagulation can have a profound influence on clot modulation of human plasma [187]. M proteins can target both intrinsic and extrinsic pathways of coagulation which are critical for the induction of fibrin clot formation [179, 188-190]. M proteins can also trigger platelet aggregation in vitro and thereby play a role in primary hemostasis. Fg was later found to be required for streptococcal-induced platelet aggregation [191]. Severe streptococcal infection is associated with $\mathrm{M}$ protein-induced platelet activation and thrombus formation [192]. M protein is a multipotent and powerful inducer of inflammation. It can also interact with Toll-like receptor 2 on human blood monocytes [193], resulting in expression of cytokines and tumor necrosis factor- $\alpha$ [194]. These proinflammatory roles of $\mathrm{M}$ proteins may explain why aggregates of $\mathrm{M}$ protein and platelets are often found at the site of infection in patients with toxic shock syndrome. GAS-associated fibrinolysis is potentially necessary for facilitating bacterial access to the vasculature [119].

5.2. Plasminogen-Mediated Bacterial Invasion. Plasminogen activation is also important for the tissue barrier degradation that allows cell migration. Through activation of metalloproteases, Pm-coated bacteria can break down extracellular matrix and basement membranes either directly or indirectly thereby facilitating bacterial spread [195]. In Salmonella enterica it has been demonstrated that $\mathrm{Pm}$ activity associated with the bacterial surface is able to degrade laminin as well as mammalian ECM and can potentiate in vitro bacterial penetration through a reconstituted BM [196]. Plg binding in Borrelia resulted in enhanced penetration of endothelial 
cell monolayers [197]. In S. aureus, $\alpha$-enolase has been suggested to play a critical role in bacterial pathogenesis by allowing its adherence to laminin-containing extracellular matrix [198]. In an infection study of bovine mammary epithelial cells by $S$. aureus, it has been reported that addition of Plg to the medium enhanced dissemination and invasiveness of bacteria [199]. Pneumococci also bind to and activate Plg via enolase which mediates transmigration across endothelial and epithelial monolayers by intercellular junction cleavage $[200,201] . \alpha$-enolase also showed enhanced monocyte migration through epithelial monolayers and promoted matrix degradation in vitro. These effects were abrogated by antibodies directed against the Plg binding site of enolase. Enolase also promotes Plg-mediated recruitment of monocytes to the acutely inflamed lung. These data suggest an important mechanism of inflammatory cell invasion mediated by increased cell-surface expression of enolase [202]. Bacillus anthracis, the causative agent of anthrax, is known to circumvent the humoral and innate immune defense of the host to initiate a productive infection. Enolase has been found to be at the helm of Plg binding which makes the Plg-bound spores capable of exhibiting antiopsonic properties by cleaving $\mathrm{C} 3 \mathrm{~b}$ molecules, in vitro, resulting in a decrease in macrophage phagocytosis [203]. This study showed that recruitment of Plg by PlgR can assist in evading host innate immunity also by the enhancement of anticomplement and antiopsonization properties of the pathogen. It is noteworthy that fibrillar surface appendages like fimbriae, flagella that have a morphological similarity to fibrin, form a major class of PlgR molecules in gramnegative bacteria, for example, E. coli. Pathogenic E. coli and S. typhimurium can bind to Plg by their thin aggregative fimbriae (curli) and/or flagellar filaments resulting in $\mathrm{Plg}$ activation by tPA $[21,22]$. These organelles have been found to adhere to ECM or BM proteins, indicating that these bacterial structures are possibly involved in the invasion of host tissues as well as promotion of bacterial colonization (reviewed in $[204,205]$ ). E. coli strains isolated from patients with ulcerative colitis showed higher affinity to various solubilized ECM proteins compared to those from healthy subjects [206]. This may indicate the existence of a positive correlation between PlgR activity and pathogenicity.

5.3. Plasminogen-Dependent Tissue Invasion by Borrelia. The importance of Pm acquisition for invasion and dissemination has been demonstrated for the vector borne spirochetes Borrelia burgdorferi. These bacteria are transmitted by ticks to human skin where they invade the outer skin layers and disseminate in the blood to cause Lyme disease [207]. They also migrate to secondary infection sites, such as the joints, the heart, and the central nervous system and, over time, Lyme disease can evolve into erosive arthritis and the destruction of ECM in the joints. Borrelia secretes two Plgbinding surface proteins-OspA and OspC [15-17] which are differentially expressed in host and ticks. In unfed ticks, OspA is highly expressed on the surface of spirochetes. After infection in mammals, OspA expression is downregulated and OspC is constitutively produced [208]. Borrelia-bound
Pm promotes degradation of soluble and insoluble components of ECM [209] and penetrates endothelial monolayers [197] including the blood-brain barrier [210]. A similar observation has been made recently with Cryptococcus where blood-brain barrier invasion by the pathogen is enhanced by functional interaction with $\mathrm{Pm}$ [7]. Studies in $\mathrm{Plg}^{-/-}$mice demonstrated that $\mathrm{Plg}$ is required for effective dissemination of Borrelia in ticks and for enhancement of spirochetemia in mice [211]. Borrelia do not produce collagenases. However, increased expression of MMPs including MMP-1, MMP-3, and MMP-9 were observed in cell culture infections with Borrelia [212-216]. It is noteworthy that surface-bound Pm in $S$. aureus activates the proteolytically active interstitial collagenase MMP-1 in a similar way [217]. Using $\mathrm{Plg}^{-/-}$ mice, it has been demonstrated that during relapsing fever from Borrelia infection, a lack of host Plg resulted in decreased spirochetal burden in the hearts, brains, and kidneys of these mice compared to WT mice. Neurological symptoms were also less common in $\mathrm{Plg}^{-/-}$mice $[218,219]$. Interestingly, there is no endogenous PA in Borrelia; instead, the bacteria use host uPA to activate surface-bound Plg. Results from these studies suggest that receptor-bound Plg promotes tissue invasion in Borrelia.

\subsection{Interaction of Helicobacter pylori with the Plasminogen} System. In vitro binding of Plg has also been reported for Helicobacter pylori isolates which is associated with severe gastrointestinal disorders including chronic gastritis, peptic ulcers, and stomach cancer [220, 221]. Binding is sensitive to lysine analogs, and bound Plg is activated by tPA [222]. H. pylori produces a dodecameric neutrophil activating protein (HP-NAP) that can potentially inhibit fibrinolytic activities [18]. This study showed that HPNAP efficiently stimulates human monocytes to synthesize tissue factor (TF) and plasminogen activator inhibitor-2 (PAI-2) without altering uPA production. Clotting assays established that tissue factor (TF) is functionally active thus triggering blood clotting and promoting fibrin deposition. As a result, the coagulation-fibrinolysis balance is shifted towards fibrin formation, prothrombotic events, and fibrin clot stabilization. This is perhaps beneficial for chronic gastritis and tissue disruption which requires tissue healing by means of degradation and removal of fibrin deposits and tissue debris. Fibrin deposition might in turn protect the bacteria against phagocytosis. In gastric cancer cells and in gastric biopsies of $H$. pylori positive patients, an increased level of PAI-2 has been demonstrated [223]. These data were also supported by the observation that in $H$. pylori-infected patients an increased level of PAI-2 and TF expression in monocytes was detected suggesting the involvement of pathogen in the regulation of the fibrinolytic balance and, hence, disease development [224]. Apart from HP-NAP, two more genes (pgbA and pgbB) encoding surface-exposed proteins with $\mathrm{Plg}$ receptor activity have been identified and characterized from H. pylori [19]. Both bind to Plg specifically in a lysine-dependent manner and enhance tPAmediated Plg activation. In both cases, Plg binding has been 
shown to be located in the conserved C-terminal region which contains two lysine residues.

5.5. Other Bacterial Pathogens and the Plasminogen System. In Porphyromonas gingivalis and the plague bacterium Yersinia pestis, plasmin inhibitors $\alpha_{2} \mathrm{AP}$ and $\alpha_{2}$ macroglobulin $\left(\alpha_{2} M\right)$ are inhibited $[225,226]$. Since both of these pathogens also activate $\mathrm{Plg}$, specific inactivation of antiproteases will therefore lead to uncontrolled Pm activity resulting in ECM and BM degradation [195]. Suppressing host antiproteases is therefore another effective mechanism undertaken by bacteria to promote proteolysis and invasion [227]. Y. pestis-derived plasminogen activator (Pla) is a surface protease responsible for the invasive character of plague. This pathogen does not express any $\mathrm{Plg}$ or $\mathrm{Pm}$ receptors; instead Pla acts as a highly efficient Plg activator [226] which proteolytically cleaves Plg similar to host uPA and tPA [3]. It is also an adhesin with affinities for ECM, laminin, and $\mathrm{BM}$ [228]. $\mathrm{Plg}^{-/-}$mice were found to be more resistant to plague infection than normal mice therefore validating the involvement of Pla in Plg activation [229].

Together, these observations clearly demonstrate that host Plg plays a critical role in pathogenesis of a broad range of invasive pathogens.

\section{Concluding Remarks}

The experimental evidence discussed here clearly demonstrates that a vast number of bacterial pathogens express PlgRs and interact with the host Plg system which in turn results in enhanced bacterial virulence. It is also clear that pathogenic bacteria can, and most often do, use the Plg system for migration across tissue barriers. Most of the identified and characterized bacterial PlgRs are multifunctional proteins involved in other important functions as well, such as adhesion, enzymatic activity, movement, interaction with immune system, myogenesis, and antiphagocytosis. It is also noteworthy to mention that a single bacterial species can express multiple PlgRs most likely due to the affinity of Plg for carboxy-terminal and internal Lys residues. Recent reports show that nonpathogenic bacteria can also express PlgRs and bind Plg via internal lysines [20, 230, 231]. Probiotic and commensal lactobacilli express an enolase, which, similar to staphylococcal enolases, interacts effectively with Plg and laminin. [232]. However, the significance of these expressions or the possible effects on colonization are not yet known.

During the last few decades various studies have suggested that there may be a correlation between the pathogenic invasion and the host haemostatic mechanisms, mainly fibrinolysis. Experimental results discussed here also demonstrate the complicated relationships of fibrinogen with invading bacteria and suggest a possible manipulation of the host fibrinolytic cascade and the receptor molecules of the pathogens to evade the host defense system. Not only is the Plg system important in controlling fibrin-containing clot degradation under physiological and pathophysiological conditions but this system can also be hijacked by bacterial pathogens to create exuberant proteolysis resulting in extracellular matrix and fibrin barrier degradation, subsequent tissue damage, and enhanced bacterial migration and invasion into the surrounding host tissue and vasculature. These properties therefore highlight the fibrinolytic system as a novel therapeutic target for controlling pathogenic invasion and dissemination.

\section{Acknowledgment}

This paper was funded by NIH (NHLBI) Grant HL13423 (to F. J. Castellino).

\section{References}

[1] M. D. P. Boyle and R. Lottenberg, "Plasminogen activation by invasive human pathogens," Thrombosis and Haemostasis, vol. 77, no. 1, pp. 1-10, 1997.

[2] J. L. Coleman and J. L. Benach, "Use of the plasminogen activation system by microorganisms," Journal of Laboratory and Clinical Medicine, vol. 134, no. 6, pp. 567-576, 1999.

[3] K. Lahteenmaki, P. Kuusela, and T. K. Korhonen, "Bacterial plasminogen activators and receptors," FEMS Microbiology Reviews, vol. 25, no. 5, pp. 531-552, 2001.

[4] H. R. Lijnen and D. Collen, "Mechanisms of physiological fibrinolysis," Bailliere's Clinical Haematology, vol. 8, no. 2, pp. 277-290, 1995.

[5] F. J. Castellino and J. R. Powell, "Human plasminogen," Methods in Enzymology, vol. 80, no. C, pp. 365-378, 1981.

[6] H. Tapiovaara, R. W. Stephens, and A. Vaheri, "Persistence of plasmin-mediated pro-urokinase activation on the surface of human monocytoid leukemia cells in vitro," International Journal of Cancer, vol. 53, no. 3, pp. 499-505, 1993.

[7] J. Stie and D. Fox, "Blood-brain barrier invasion by Cryptococcus neoformans is enhanced by functional interactions with plasmin," Microbiology, vol. 158, no. 1, pp. 240-258, 2012.

[8] Y. A. Declerck and W. E. Laug, "Cooperation between matrix metalloproteinases and the plasminogen activator-plasmin system in tumor progression," Enzyme and Protein, vol. 49, no. 1-3, pp. 72-84, 1996.

[9] H. R. Lijnen and D. Collen, "Role of the plasminogen and MMP systems in wound healing," in Plasminogen: Structure, Activation, and Regulation, D. M. Waisman, Ed., pp. 189-200, Plenum, New York, NY, USA, 2003.

[10] V. Pancholi and V. A. Fischetti, " $\alpha$-enolase, a novel strong plasmin(ogen) binding protein on the surface of pathogenic streptococci," Journal of Biological Chemistry, vol. 273, no. 23, pp. 14503-14515, 1998.

[11] S. B. Winram and R. Lottenberg, "The plasmin-binding protein Plr of group A streptococci is identified as glyceraldehyde-3-phosphate dehydrogenase," Microbiology, vol. 142, no. 8, pp. 2311-2320, 1996.

[12] G. Boël, H. Jin, and V. Pancholi, "Inhibition of cell surface export of group A streptococcal anchorless surface dehydrogenase affects bacterial adherence and antiphagocytic properties," Infection and Immunity, vol. 73, no. 10, pp. 62376248, 2005.

[13] A. Berge and U. Sjobring, "PAM, a novel plasminogen-binding protein from Streptococcus pyogenes," Journal of Biological Chemistry, vol. 268, no. 34, pp. 25417-25424, 1993. 
[14] U. Ringdahl and U. Sjöbring, "Analysis of plasminogen-binding M proteins of Streptococcus pyogenes," Methods, vol. 21, no. 2, pp. 143-150, 2000.

[15] H. Fuchs, R. Wallich, M. M. Simon, and M. D. Kramer, "The outer surface protein A of the spirochete Borrelia burgdorferi is a plasmin(ogen) receptor," Proceedings of the National Academy of Sciences of the United States of America, vol. 91, no. 26, pp. 12594-12598, 1994.

[16] M. S. Klempner, R. Noring, M. P. Epstein et al., "Binding of human plasminogen and urokinase-type plasminogen activator to the Lyme disease spirochete, Borrelia burgdorferi," Journal of Infectious Diseases, vol. 171, no. 5, pp. 1258-1265, 1995.

[17] L. T. Hu, G. Perides, R. Noring, and M. S. Klempner, "Binding of human plasminogen to Borrelia burgdorferi," Infection and Immunity, vol. 63, no. 9, pp. 3491-3496, 1995.

[18] P. Montemurro, G. Barbuti, W. G. Dundon et al., "Helicobacter pylori neutrophil-activating protein stimulates tissue factor and plasminogen activator inhibitor-2 production by human blood mononuclear cells," Journal of Infectious Diseases, vol. 183, no. 7, pp. 1055-1062, 2001.

[19] K. Jönsson, B. P. Guo, H. J. Monstein, J. J. Mekalanos, and G. Kronvall, "Molecular cloning and characterization of two Helicobacter pylori genes coding for plasminogen-binding proteins," Proceedings of the National Academy of Sciences of the United States of America, vol. 101, no. 7, pp. 1852-1857, 2004.

[20] M. Candela, M. Centanni, J. Fiori et al., "DnaK from Bifidobacterium animalis subsp. lactis is a surface-exposed human plasminogen receptor upregulated in response to bile salts," Microbiology, vol. 156, no. 6, pp. 1609-1618, 2010.

[21] K. Lahteenmaki, B. Westerlund, P. Kuusela, and T. K. Korhonen, "Immobilization of plasminogen on Escherichia coli flagella," FEMS Microbiology Letters, vol. 106, no. 3, pp. 309-314, 1993.

[22] U. Sjobring, G. Pohl, and A. Olsen, "Plasminogen, absorbed by Escherichia coli expressing curli or by Salmonella enteritidis expressing thin aggregative fimbriae, can be activated by simultaneously captured tissue-type plasminogen activator (t-PA)," Molecular Microbiology, vol. 14, no. 3, pp. 443-452, 1994.

[23] R. Lottenberg, D. Minning-Wenz, and M. D. P. Boyle, "Capturing host plasmin(ogen): a common mechanism for invasive pathogens?" Trends in Microbiology, vol. 2, no. 1, pp. 20-24, 1994.

[24] Z. Li, V. A. Ploplis, E. L. French, and M. D. P. Boyle, "Interaction between group A streptococci and the plasmin(ogen) system promotes virulence in a mouse skin infection model," Journal of Infectious Diseases, vol. 179, no. 4, pp. 907-914, 1999.

[25] M. Forsgren, B. Raden, and M. Israelsson, "Molecular cloning and characterization of a full-length cDNA clone for human plasminogen," FEBS Letters, vol. 213, no. 2, pp. 254260, 1987.

[26] D. Raum, D. Marcus, and C. A. Alper, "Synthesis of human plasminogen by the liver," Science, vol. 208, no. 4447, pp. 1036-1037, 1980.

[27] W. R. Ji, L. G. Barrientos, M. Llinás et al., "Selective inhibition by kringle 5 of human plasminogen on endothelial cell migration, an important process in angiogenesis," Biochemical and Biophysical Research Communications, vol. 247, no. 2, pp. 414-419, 1998.
[28] J. I. Weidong-Richard, F. J. Castellino, Y. Chang et al., "Characterization of kringle domains of angiostatin as antagonists of endothelial cell migration, an important process in angiogenesis," FASEB Journal, vol. 12, no. 15, pp. 1731-1738, 1998.

[29] M. A. A. Parry, X. C. Zhang, and W. Bode, "Molecular mechanisms of plasminogen activation: bacterial cofactors provide clues," Trends in Biochemical Sciences, vol. 25, no. 2, pp. 5359, 2000.

[30] L. C. Sehl and F. J. Castellino, "Thermodynamic properties of the binding of $\alpha$-, $\omega$-amino acids to the isolated kringle 4 region of human plasminogen as determined by high sensitivity titration calorimetry," Journal of Biological Chemistry, vol. 265, no. 10, pp. 5482-5486, 1990.

[31] N. Menhart, L. C. Sehl, R. F. Kelley, and F. J. Castellino, "Construction, expression, and purification of recombinant kringle 1 of human plasminogen and analysis of its interaction with omega-amino acids," Biochemistry, vol. 30, pp. 1948-1957, 1991.

[32] N. Menhart, S. G. McCance, L. C. Sehl, and F. J. Castellino, "Functional independence of the kringle 4 and kringle 5 regions of human plasminogen," Biochemistry, vol. 32, no. 34, pp. 8799-8806, 1993.

[33] N. Menhart and F. J. Castellino, "The importance of the hydrophobic components of the binding energies in the interaction of $\omega$-amino acid ligands with isolated kringle polypeptide domains of human plasminogen," International Journal of Peptide and Protein Research, vol. 46, no. 6, pp. 464470, 1995.

[34] D. N. Marti, J. Schaller, and M. Llinás, "Solution structure and dynamics of the plasminogen kringle 2-AMCHA complex: 31-helix in homologous domains," Biochemistry, vol. 38, no. 48, pp. 15741-15755, 1999.

[35] A. C. Wistedt, H. Kotarsky, D. Marti et al., "Kringle 2 mediates high affinity binding of plasminogen to an internal sequence in streptococcal surface protein PAM," Journal of Biological Chemistry, vol. 273, no. 38, pp. 24420-24424, 1998.

[36] T. Urano, V. S. De Serrano, B. A. K. Chibber, and F. J. Castellino, "The control of the urokinase-catalyzed activation of human glutamic acid 1-plasminogen by positive and negative effectors," Journal of Biological Chemistry, vol. 262, no. 33, pp. 15959-15964, 1987.

[37] T. Urano, B. A. K. Chibber, and F. J. Castellino, "The reciprocal effects of $\varepsilon$-aminohexanoic acid and chloride ion on the activation of human [Glul]plasminogen by human urokinase," Proceedings of the National Academy of Sciences of the United States of America, vol. 84, no. 12, pp. 4031-4034, 1987.

[38] G. J. Hoover, N. Menhart, A. Martin, S. Warder, and F. J. Castellino, "Amino acids of the recombinant kringle 1 domain of human plasminogen that stabilize its interaction with $\omega$-amino acids," Biochemistry, vol. 32, no. 41, pp. 1093610943, 1993.

[39] S. G. McCance and F. J. Castellino, "Contributions of individual kringle domains toward maintenance of the chloride-induced tight conformation of human glutamic acid-1 plasminogen," Biochemistry, vol. 34, no. 29, pp. 95819586, 1995.

[40] N. Menhart, G. J. Hoover, S. G. McCance, and F. J. Castellino, "Roles of individual kringle domains in the functioning of positive and negative effectors of human plasminogen activation," Biochemistry, vol. 34, no. 5, pp. 1482-1488, 1995. 
[41] B. N. Violand, J. M. Sodetz, and F. J. Castellino, "The effect of $\varepsilon$ amino caproic acid on the gross conformation of plasminogen and plasmin," Archives of Biochemistry and Biophysics, vol. 170, no. 1, pp. 300-305, 1975.

[42] A. J. G. Horrevoets, A. E. Smilde, J. C. Fredenburgh, H. Pannekoek, and M. E. Nesheim, "The activation-resistant conformation of recombinant human plasminogen is stabilized by basic residues in the amino-terminal hinge region," Journal of Biological Chemistry, vol. 270, no. 26, pp. 15770 15776, 1995.

[43] H. Claeys and J. Vermylen, "Physico chemical and proenzyme properties of $\mathrm{NH}_{2}$ terminal glutamic acid and $\mathrm{NH}_{2}$ terminal lysine human plasminogen. Influence of 6 aminohexanoic acid," Biochimica et Biophysica Acta, vol. 342, no. 2, pp. 351359, 1974.

[44] I. I. Mathews, P. Vanderhoff-Hanaver, F. J. Castellino, and A. Tulinsky, "Crystal structures of the recombinant kringle 1 domain of human plasminogen in complexes with the ligands $\varepsilon$-aminocaproic acid and trans-4-(aminomethyl) cyclohexane-1-carboxylic acid," Biochemistry, vol. 35, no. 8, pp. 2567-2576, 1996.

[45] A. M. Mulichak, A. Tulinsky, and K. G. Ravichandran, "Crystal and molecular structure of human plasminogen kringle 4 refined at 1.9- $\AA$ resolution," Biochemistry, vol. 30, no. 43, pp. 10576-10588, 1991.

[46] Y. Chang, I. Mochalkin, S. G. McCance, B. Cheng, A. Tulinsky, and F. J. Castellino, "Structure and ligand binding determinants of the recombinant kringle 5 domain of human plasminogen," Biochemistry, vol. 37, no. 10, pp. 3258-3271, 1998.

[47] E. Peisach, J. Wang, T. L. De Santos, E. Reich, and D. Ringe, "Crystal structure of the proenzyme domain of plasminogen," Biochemistry, vol. 38, no. 34, pp. 11180-11188, 1999.

[48] X. Wang, S. Terzyan, J. Tang, J. A. Loy, X. Lin, and X. C. Zhang, "Human plasminogen catalytic domain undergoes an unusual conformational change upon activation," Journal of Molecular Biology, vol. 295, no. 4, pp. 903-914, 2000.

[49] R. H. P. Law, T. Caradoc-Davies, N. Cowieson et al., "The Xray crystal structure of full-length human plasminogen," Cell Reports, vol. 1, no. 3, pp. 185-190, 2012.

[50] M. C. Abad, R. K. Arni, D. K. Grella, F. J. Castellino, A. Tulinsky, and J. H. Geiger, "The X-ray crystallographic structure of the angiogenesis inhibitor angiostatin," Journal of Molecular Biology, vol. 318, no. 4, pp. 1009-1017, 2002.

[51] Y. Xue, C. Bodin, and K. Olsson, "Crystal structure of the native plasminogen reveals an activation-resistant compact conformation," Journal of Thrombosis and Haemostasis, vol. 10, no. 7, pp. 1385-1396, 2012.

[52] K. Danø, P. A. Andreasen, J. Grøndahl-Hansen, P. Kristensen, L. S. Nielsen, and L. Skriver, "Plasminogen activators, tissue degradation, and cancer," Advances in Cancer Research, vol. 44, no. C, pp. 139-266, 1985.

[53] J. D. Vassalli, J. M. Dayer, A. Wohlwend, and D. Belin, "Concomitant secretion of prourokinase and of a plasminogen activator-specific inhibitor by cultured human monocytesmacrophages," Journal of Experimental Medicine, vol. 159, no. 6, pp. 1653-1668, 1984.

[54] P. A. Andreasen, L. S. Nielsen, and P. Kristensen, "Plasminogen activator inhibitor from human fibrosarcoma cells binds urokinase-type plasminogen activator, but not its proenzyme," Journal of Biological Chemistry, vol. 261, no. 17, pp. 7644-7651, 1986.
[55] O. Saksela, "Plasminogen activation and regulation of pericellular proteolysis," Biochimica et Biophysica Acta, vol. 823, no. 1, pp. 35-65, 1985.

[56] D. C. Rijken, "Plasminogen activators and plasminogen activator inhibitors: biochemical aspects," Bailliere's Clinical Haematology, vol. 8, no. 2, pp. 291-312, 1995.

[57] D. Lamba, M. Bauer, R. Huber et al., "The $2.3 \AA$ crystal structure of the catalytic domain of recombinant twochain human tissue-type plasminogen activator," Journal of Molecular Biology, vol. 258, no. 1, pp. 117-135, 1996.

[58] G. Spraggon, C. Phillips, U. K. Nowak et al., "The crystal structure of the catalytic domain of human urokinase-type plasminogen activator," Structure, vol. 3, no. 7, pp. 681-691, 1995.

[59] E. Appella, E. A. Robinson, and S. J. Ullrich, "The receptorbinding sequence of urokinase. A biological function for the growth-factor module of proteases," Journal of Biological Chemistry, vol. 262, no. 10, pp. 4437-4440, 1987.

[60] J. H. Verheijen, M. P. Caspers, G. T. Chang, G. A. de Munk, P. H. Pouwels, and B. E. Enger-Valk, "Involvement of finger domain and kringle 2 domain of tissue-type plasminogen activator in fibrin binding and stimulation of activity by fibrin,” EMBO Journal, vol. 5, no. 13, pp. 3525-3530, 1986.

[61] F. Blasi, J. D. Vassalli, and K. Dano, "Urokinase-type plasminogen activator: proenzyme, receptor, and inhibitors," Journal of Cell Biology, vol. 104, no. 4, pp. 801-804, 1987.

[62] D. Alfano, P. Franco, I. Vocca et al., "The urokinase plasminogen activator and its receptor. Role in cell growth and apoptosis," Thrombosis and Haemostasis, vol. 93, no. 2, pp. 205-211, 2005.

[63] V. Ellis, N. Behrendt, and K. Dano, "Plasminogen activation by receptor-bound urokinase: a kinetic study with both cell-associated and isolated receptor," Journal of Biological Chemistry, vol. 266, no. 19, pp. 12752-12758, 1991.

[64] M. P. Crippa, “Urokinase-type plasminogen activator," International Journal of Biochemistry and Cell Biology, vol. 39, no. 4, pp. 690-694, 2007.

[65] M. Ranby, N. Bergsdorf, and T. Nilsson, "Enzymatic properties of the one- and two-chain form of tissue plasminogen activator," Thrombosis Research, vol. 27, no. 2, pp. 175-183, 1982.

[66] M. Hoylaerts, D. C. Rijken, H. R. Lijnen, and D. Collen, "Kinetics of the activation of plasminogen by human tissue plasminogen activator. Role of fibrin," Journal of Biological Chemistry, vol. 257, no. 6, pp. 2912-2919, 1982.

[67] P. Carmeliet, L. Schoonjans, L. Kieckens et al., "Physiological consequences of loss of plasminogen activator gene function in mice," Nature, vol. 368, no. 6470, pp. 419-424, 1994.

[68] M. Zhuo, D. M. Holtzman, Y. Li et al., "Role of tissue plasminogen activator receptor LRP in hippocampal longterm potentiation," Journal of Neuroscience, vol. 20, no. 2, pp. 542-549, 2000.

[69] X. Wang, S. R. Lee, K. Arai et al., "Lipoprotein receptormediated induction of matrix metalloproteinase by tissue plasminogen activator," Nature Medicine, vol. 9, no. 10, pp. 1313-1317, 2003.

[70] N. W. Seeds, M. E. Basham, and S. P. Haffke, "Neuronal migration is retarded in mice lacking the tissue plasminogen activator gene," Proceedings of the National Academy of Sciences of the United States of America, vol. 96, no. 24, pp. 14118-14123, 1999.

[71] K. A. Hajjar and N. M. Hamel, "Identification and characterization of human endothelial cell membrane binding sites 
for tissue plasminogen activator and urokinase," Journal of Biological Chemistry, vol. 265, no. 5, pp. 2908-2916, 1990.

[72] K. A. Hajjar, "The endothelial cell tissue plasminogen activator receptor: specific interaction with plasminogen," Journal of Biological Chemistry, vol. 266, no. 32, pp. 2196221970, 1991.

[73] K. A. Hajjar, A. T. Jacovina, and J. Chacko, "An endothelial cell receptor for plasminogen/tissue plasminogen activator. I. Identity with annexin II," Journal of Biological Chemistry, vol. 269, no. 33, pp. 21191-21197, 1994.

[74] K. A. Hajjar and S. Krishnan, "Annexin II: a mediator of the plasmin/plasminogen activator system," Trends in Cardiovascular Medicine, vol. 9, no. 5, pp. 128-138, 1999.

[75] G. M. Cesarman, C. A. Guevara, and K. A. Hajjar, "An endothelial cell receptor for plasminogen/tissue plasminogen activator (t-PA). II. Annexin II-mediated enhancement of tPA-dependent plasminogen activation," Journal of Biological Chemistry, vol. 269, no. 33, pp. 21198-21203, 1994.

[76] G. Kassam, B. H. Le, K. S. Choi et al., "The p11 subunit of the annexin II tetramer plays a key role in the stimulation of t-PA-dependent plasminogen activation," Biochemistry, vol. 37, no. 48, pp. 16958-16966, 1998.

[77] H. M. Kang, K. S. Choi, G. Kassam, S. L. Fitzpatrick, M. Kwon, and D. M. Waisman, "Role of Annexin II tetramer in plasminogen activation," Trends in Cardiovascular Medicine, vol. 9, no. 3-4, pp. 92-102, 1999.

[78] K. A. Hajjar, L. Mauri, A. T. Jacovina et al., "Tissue plasminogen activator binding to the annexin II tail domain: direct modulation by homocysteine," Journal of Biological Chemistry, vol. 273, no. 16, pp. 9987-9993, 1998.

[79] M. Kwon, T. J. MacLeod, Y. Zhang, and D. M. Waisman, "S100A10, annexin A2, and annexin A2 heterotetramer as candidate plasminogen receptors," Frontiers in Bioscience, vol. 10, no. 1, pp. 300-325, 2005.

[80] A. P. Surette, P. A. Madureira, K. D. Phipps, V. A. Miller, P. Svenningsson, and D. M. Waisman, "Regulation of fibrinolysis by S100A10 in vivo," Blood, vol. 118, no. 11, pp. 31723181, 2011.

[81] U. Beisiegel, W. Weber, G. Ihrke, J. Herz, and K. K. Stanley, "The LDL-receptor-related protein, LRP, is an apolipoprotein E-binding protein," Nature, vol. 341, no. 6238, pp. 162-164, 1989.

[82] M. S. Brown, J. Herz, R. C. Kowal, and J. L. Goldstein, “The low-density lipoprotein receptor-related protein: double agent or decoy?" Current Opinion in Lipidology, vol. 2, no. 2, pp. 65-72, 1991.

[83] S. K. Moestrup, “The $\alpha 2$-macroglobulin receptor and epithelial glycoprotein-330: two giant receptors mediating endocytosis of multiple ligands," Biochimica et Biophysica Acta, vol. 1197, no. 2, pp. 197-213, 1994.

[84] J. C. Zhang, R. Sakthivel, D. Kniss, C. H. Graham, D. K. Strickland, and K. R. McCrae, "The low density lipoprotein receptor-related protein $/ \alpha 2$-macroglobulin receptor regulates cell surface plasminogen activator activity on human trophoblast cells," Journal of Biological Chemistry, vol. 273, no. 48, pp. 32273-32280, 1999.

[85] E. Hahn-Dantona, J. F. Ruiz, P. Bornstein, and D. K. Strickland, "The low density lipoprotein receptor-related protein modulates levels of matrix metalloproteinase 9 (MMP-9) by mediating its cellular catabolism," Journal of Biological Chemistry, vol. 276, no. 18, pp. 15498-15503, 2001.
[86] R. W. Colman, "Activation of plasminogen by human plasma kallikrein," Biochemical and Biophysical Research Communications, vol. 35, no. 2, pp. 273-279, 1969.

[87] G. H. Goldsmith, H. Saito, and O. D. Ratnoff, "The activation of plasminogen by Hageman factor (Factor XII) and Hageman factor fragments," Journal of Clinical Investigation, vol. 62, no. 1, pp. 54-60, 1978.

[88] M. S. Stack, T. L. Moser, and S. V. Pizzo, "Binding of human plasminogen to basement-membrane (type IV) collagen," Biochemical Journal, vol. 284, no. 1, pp. 103-108, 1992.

[89] J. Römisch, S. Vermöhlen, A. Feussner, and H. A. Stöhr, “The FVII activating protease cleaves single-chain plasminogen activators," Haemostasis, vol. 29, no. 5, pp. 292-299, 2000.

[90] H. R. Lijnen, M. Hoylaerts, and D. Collen, "Isolation and characterization of a human plasma protein with affinity for the lysine binding sites in plasminogen. Role in the regulation of fibrinolysis and identification as histidine-rich glycoprotein," Journal of Biological Chemistry, vol. 255, no. 21, pp. 10214-10222, 1980.

[91] D. B. Borza and W. T. Morgan, "Acceleration of plasminogen activation by tissue plasminogen activator on surface-bound histidine-proline-rich glycoprotein," Journal of Biological Chemistry, vol. 272, no. 9, pp. 5718-5726, 1997.

[92] J. Travis and G. S. Salvesen, "Human plasma proteinase inhibitors," Annual Review of Biochemistry, vol. 52, pp. 655709, 1983.

[93] D. A. Lawrence, "The serpin-proteinase complex revealed," Nature Structural Biology, vol. 4, no. 5, pp. 339-341, 1997.

[94] J. Potempa, E. Korzus, and J. Travis, "The serpin superfamily of proteinase inhibitors: structure, function, and regulation," Journal of Biological Chemistry, vol. 269, no. 23, pp. 1595715960, 1994.

[95] B. Wiman and D. Collen, "On the mechanism of the reaction between human $\alpha 2$-antiplasmin and plasmin," Journal of Biological Chemistry, vol. 254, no. 18, pp. 9291-9297, 1979.

[96] N. Aoki, M. Moroi, and K. Tachiya, "Effects of $\alpha 2$-plasmin inhibitor on fibrin clot lysis. Its comparison with $\alpha 2$ macroglobulin," Thrombosis and Haemostasis, vol. 39, no. 1, pp. 22-31, 1978.

[97] X. Wang, X. Lin, J. A. Loy, J. Tang, and X. C. Zhang, "Crystal structure of the catalytic domain of human plasmin complexed with streptokinase," Science, vol. 281, no. 5383, pp. 1662-1665, 1998.

[98] A. Rabijns, H. L. De Bondt, and C. De Ranter, "Threedimensional structure of staphylokinase, a plasminogen activator with therapeutic potential," Nature Structural Biology, vol. 4, no. 5, pp. 357-360, 1997.

[99] D. Collen, "Staphylokinase: a potent, uniquely fibrinselective thrombolytic agent," Nature Medicine, vol. 4, no. 3, pp. 279-284, 1998.

[100] P. M. Schlievert, A. P. Assimacopoulos, and P. P. Cleary, "Severe invasive group A streptococcal disease: clinical description and mechanisms of pathogenesis," Journal of Laboratory and Clinical Medicine, vol. 127, no. 1, pp. 13-22, 1996.

[101] G. Molinari and G. S. Chhatwal, "Streptococcal invasion," Current Opinion in Microbiology, vol. 2, no. 1, pp. 56-61, 1999.

[102] G. S. Chhatwal and D. J. McMillan, "Uncovering the mysteries of invasive streptococcal diseases," Trends in Molecular Medicine, vol. 11, no. 4, pp. 152-155, 2005.

[103] J. Khil, M. Im, A. Heath et al., "Plasminogen enhances virulence of group A streptococci by streptokinase-dependent 
and streptokinase-independent mechanisms," Journal of Infectious Diseases, vol. 188, no. 4, pp. 497-505, 2003.

[104] K. N. N. Reddy, "Streptokinase-biochemistry and clinical application," Enzyme, vol. 40, no. 2-3, pp. 79-89, 1988.

[105] J. A. Loy, X. Lin, M. Schenone, F. J. Castellino, X. C. Zhang, and J. Tang, "Domain interactions between streptokinase and human plasminogen," Biochemistry, vol. 40, no. 48, pp. 14686-14695, 2001.

[106] P. Zhai, N. Wakeham, J. A. Loy, and X. C. Zhang, "Functional roles of streptokinase C-terminal flexible peptide in active site formation and substrate recognition in plasminogen activation," Biochemistry, vol. 42, no. 1, pp. 114-120, 2003.

[107] K. C. Young, G. Y. Shi, D. H. Wu et al., "Plasminogen activation by streptokinase via a unique mechanism," Journal of Biological Chemistry, vol. 273, no. 5, pp. 3110-3116, 1998.

[108] H. Wang, R. Lottenberg, and M. D. P. Boyle, "Analysis of the interaction of group A streptococci with fibrinogen, streptokinase and plasminogen," Microbial Pathogenesis, vol. 18, no. 3, pp. 153-166, 1995.

[109] L. F. Lin, A. Houng, and G. L. Reed, "Epsilon amino caproic acid inhibits streptokinase-plasminogen activator complex formation and substrate binding through kringle-dependent mechanisms," Biochemistry, vol. 39, no. 16, pp. 4740-4745, 2000.

[110] P. D. Boxrud and P. E. Bock, "Streptokinase binds preferentially to the extended conformation of plasminogen through lysine binding site and catalytic domain interactions," Biochemistry, vol. 39, no. 45, pp. 13974-13981, 2000.

[111] R. R. Bean, I. M. Verhamme, and P. E. Bock, "Role of the streptokinase $\alpha$-domain in the interactions of streptokinase with plasminogen and plasmin," Journal of Biological Chemistry, vol. 280, no. 9, pp. 7504-7510, 2005.

[112] M. Dahiya, G. Rajamohan, and K. L. Dikshit, "Enhanced plasminogen activation by staphylokinase in the presence of streptokinase $\beta / \beta \gamma$ domains: plasminogen kringles play a role," FEBS Letters, vol. 579, no. 7, pp. 1565-1572, 2005.

[113] D. J. Davidson, D. L. Higgins, and F. J. Castellino, "Plasminogen activator activities of equimolar complexes of streptokinase with variant recombinant plasminogens," Biochemistry, vol. 29, no. 14, pp. 3585-3590, 1990.

[114] F. Conejero-Lara, J. Parrado, A. I. Azuaga, C. M. Dobson, and C. P. Ponting, "Analysis of the interactions between streptokinase domains and human plasminogen," Protein Science, vol. 7, no. 10, pp. 2190-2199, 1998.

[115] V. A. Ploplis and F. J. Castellino, "Nonfibrinolytic functions of plasminogen," Methods, vol. 21, no. 2, pp. 103-110, 2000.

[116] F. J. Castellino and V. A. Ploplis, "Structure and function of the plasminogen/plasmin system," Thrombosis and Haemostasis, vol. 93, no. 4, pp. 647-654, 2005.

[117] L. Summaria, L. Arzadon, P. Bernabe, and K. C. Robbins, "The interaction of streptokinase with human, cat, dog, and rabbit plasminogens. The fragmentation of streptokinase in the equimolar plasminogen streptokinase complexes," Journal of Biological Chemistry, vol. 249, no. 15, pp. 47604769, 1974.

[118] M. Gonzalez-Gronow, G. E. Sierfring, and F. J. Castellino, "Mechanism of activation of human plasminogen by the activator complex, streptokinase plasmin," Journal of Biological Chemistry, vol. 253, no. 4, pp. 1090-1094, 1978.

[119] H. Sun, U. Ringdahl, J. W. Momeister et al., "Plasminogen is a critical host pathogenicity factor for group A streptococcal infection," Science, vol. 305, no. 5688, pp. 1283-1286, 2004.
[120] D. Collen, B. Schlott, Y. Engelborghs et al., "On the mechanism of the activation of human plasminogen by recombinant staphylokinase," Journal of Biological Chemistry, vol. 268, no. 11, pp. 8284-8289, 1993.

[121] H. R. Lijnen, F. De Cock, B. Van Hoef, B. Schlott, and D. Collen, "Characterization of the interaction between plasminogen and staphylokinase," European Journal of Biochemistry, vol. 224, no. 1, pp. 143-149, 1994.

[122] B. Schlott, M. Hartmann, K. H. Guhrs et al., "Functional properties of recombinant staphylokinase variants obtained by site-specific mutagenesis of methionine-26," Biochimica et Biophysica Acta, vol. 1204, no. 2, pp. 235-242, 1994.

[123] T. Mölkänen, J. Tyynelä, J. Helin, N. Kalkkinen, and P. Kuusela, "Enhanced activation of bound plasminogen on Staphylococcus aureus by staphylokinase," FEBS Letters, vol. 517, no. 1-3, pp. 72-78, 2002.

[124] B. Schlott, K. H. Gührs, M. Hartmann, A. Röcker, and D. Collen, "NH2-terminal structural motifs in staphylokinase required for plasminogen activation," Journal of Biological Chemistry, vol. 273, no. 35, pp. 22346-22350, 1998.

[125] K. Okada, S. Ueshima, T. Takaishi, H. Yuasa, H. Fukao, and O. Matsuo, "Effects of fibrin and $\alpha_{2}$-Antiplasmin on plasminogen activation by staphylokinase," American Journal of Hematology, vol. 53, no. 3, pp. 151-157, 1996.

[126] D. V. Sakharov, H. R. Lijnen, and D. C. Rijken, "Interactions between staphylokinase, plasmin(ogen), and fibrin. Staphylokinase discriminates between free plasminogen and plasminogen bound to partially degraded fibrin," Journal of Biological Chemistry, vol. 271, no. 44, pp. 27912-27918, 1996.

[127] P. A. M. Warmerdam, K. Vanderlick, P. Vandervoort et al., "Staphylokinase-specific cell-mediated immunity in humans," Journal of Immunology, vol. 168, no. 1, pp. 155$161,2002$.

[128] T. Jin, M. Bokarewa, T. Foster, J. Mitchell, J. Higgins, and A. Tarkowski, "Staphylococcus aureus resists human defensins by production of staphylokinase, a novel bacterial evasion mechanism," Journal of Immunology, vol. 172, no. 2, pp. 1169-1176, 2004.

[129] M. Ullberg, G. Kronvall, I. Karlsson, and B. Wiman, "Receptors for human plasminogen on gram-negative bacteria," Infection and Immunity, vol. 58, no. 1, pp. 21-25, 1990.

[130] E. F. Plow, D. E. Freaney, J. Plescia, and L. A. Miles, "The plasminogen system and cell surfaces: evidence for plasminogen and urokinase receptors on the same cell type," Journal of Cell Biology, vol. 103, no. 6 I, pp. 2411-2420, 1986.

[131] D. Rouy and E. Angles-Cano, "The mechanism of activation of plasminogen at the fibrin surface by tissue-type plasminogen activator in a plasma milieu in vitro. Role of $\alpha 2$ antiplasmin," Biochemical Journal, vol. 271, no. 1, pp. 51-57, 1990.

[132] S. Bergmann, M. Rohde, G. S. Chhatwal, and S. Hammerschmidt, " $\alpha$-Enolase of Streptococcus pneumoniae is a plasmin(ogen)-binding protein displayed on the bacterial cell surface," Molecular Microbiology, vol. 40, no. 6, pp. 12731287, 2001.

[133] S. Bergmann, M. Rohde, and S. Hammerschmidt, "Glyceraldehyde-3-phosphate dehydrogenase of Streptococcus pneumoniae is a surface-displayed plasminogen-binding protein," Infection and Immunity, vol. 72, no. 4, pp. 2416-2419, 2004.

[134] A. Lama, A. Kucknoor, V. Mundodi, and J. F. Alderete, "Glyceraldehyde-3-phosphate dehydrogenase is a surfaceassociated, fibronectin-binding protein of Trichomonas vaginalis," Infection and Immunity, vol. 77, no. 7, pp. 2703-2711, 2009. 
[135] L. Egea, L. Aguilera, R. Giménez et al., "Role of secreted glyceraldehyde-3-phosphate dehydrogenase in the infection mechanism of enterohemorrhagic and enteropathogenic Escherichia coli: interaction of the extracellular enzyme with human plasminogen and fibrinogen," International Journal of Biochemistry and Cell Biology, vol. 39, no. 6, pp. 1190-1203, 2007.

[136] S. B. Winram and R. Lottenberg, "Site-directed mutagenesis of streptococcal plasmin receptor protein (Plr) identifies the C-terminal Lys334 as essential for plasmin binding, but mutation of the plr gene does not reduce plasmin binding to group A streptococci," Microbiology, vol. 144, no. 8, pp. 2025 2035, 1998.

[137] S. K. Matta, S. Agarwal, and R. Bhatnagar, "Surface localized and extracellular Glyceraldehyde-3-phosphate dehydrogenase of Bacillus anthracis is a plasminogen binding protein," Biochimica et Biophysica Acta, vol. 1804, no. 11, pp. 21112120, 2010.

[138] H. Jin, Y. P. Song, G. Boel, J. Kochar, and V. Pancholi, "Group A streptococcal surface GAPDH, SDH, recognizes uPAR/CD87 as its receptor on the human pharyngeal cell and mediates bacterial adherence to host cells," Journal of Molecular Biology, vol. 350, no. 1, pp. 27-41, 2005.

[139] V. Pancholi and V. A. Fischetti, "Regulation of the phosphorylation of human pharyngeal cell proteins by group A streptococcal surface dehydrogenase: signal transduction between streptococci and pharyngeal cells," Journal of Experimental Medicine, vol. 186, no. 10, pp. 1633-1643, 1997.

[140] V. Pancholi and V. A. Fischetti, "Cell-to-cell signalling between group a streptococci and pharyngeal cells - Role of streptococcal surface dehydrogenase (SDH)," Advances in Experimental Medicine and Biology, vol. 418, pp. 499-504, 1997.

[141] M. Piast, I. Kustrzeba-Wójcicka, M. Matusiewicz, and T. Banaś, "Molecular evolution of enolase," Acta Biochimica Polonica, vol. 52, no. 2, pp. 507-513, 2005.

[142] C. C. Rider and C. B. Taylor, "Enolase isoenzymes. II. Hybridization studies, developmental and phylogenetic aspects," Biochimica et Biophysica Acta, vol. 405, no. 1, pp. 175-187, 1975.

[143] L. Fletcher, C. C. Rider, and C. B. Taylor, "Enolase isoenzymes. III. Chromatographic and immunological characteristics of rat brain enolase," Biochimica et Biophysica Acta, vol. 452, no. 1, pp. 245-252, 1976.

[144] V. Pancholi, "Multifunctional $\alpha$-enolase: its role in diseases," Cellular and Molecular Life Sciences, vol. 58, no. 7, pp. 902 920, 2001.

[145] S. Ehinger, W. D. Schubert, S. Bergmann, S. Hammerschmidt, and D. W. Heinz, "Plasmin(ogen)-binding $\alpha$ Enolase from Streptococcus pneumoniae: crystal structure and evaluation of plasmin(ogen)-binding sites," Journal of Molecular Biology, vol. 343, no. 4, pp. 997-1005, 2004.

[146] H. J. Kang, S. K. Jung, S. J. Kim, and S. J. Chung, "Structure of human $\alpha$-enolase (hENO1), a multifunctional glycolytic enzyme," Acta Crystallographica Section D, vol. 64, no. 6, pp. 651-657, 2008.

[147] S. Bergmann, M. Rohde, G. S. Chhatwal, and S. Hammerschmidt, "Characterization of plasmin(ogen) binding to Streptococcus pneumoniae," Indian Journal of Medical Research, vol. 119, supplement, pp. 29-32, 2004.

[148] R. Lopez-Alemany, M. Suelves, A. Diaz-Ramos, B. Vidal, and P. Munoz-Canoves, "Alpha-enolase plasminogen receptor in myogenesis," Frontiers in Bioscience, vol. 10, no. 1, pp. 30-36, 2005.
[149] M. Capello, S. Ferri-Borgogno, P. Cappello, and F. Novelli, " $\alpha$-enolase: a promising therapeutic and diagnostic tumor target," FEBS Journal, vol. 278, no. 7, pp. 1064-1074, 2011.

[150] V. Pancholi and V. A. Fischetti, "A novel plasminogen/ plasmin binding protein on the surface of group A streptococci," Advances in Experimental Medicine and Biology, vol. 418, pp. 597-599, 1997.

[151] A. Jolodar, P. Fischer, S. Bergmann, D. W. Büttner, S. Hammerschmidt, and N. W. Brattig, "Molecular cloning of an $\alpha$ enolase from the human filarial parasite Onchocerca volvulus that binds human plasminogen," Biochimica et Biophysica Acta, vol. 1627, no. 2-3, pp. 111-120, 2003.

[152] A. Y. Jong, S. H. M. Chen, M. F. Stins, K. S. Kim, T. L. Tuan, and S. H. Huang, "Binding of Candida albicans enolase to plasmin(ogen) results in enhanced invasion of human brain microvascular endothelial cells," Journal of Medical Microbiology, vol. 52, no. 8, pp. 615-622, 2003.

[153] L. A. Miles, C. M. Dahlberg, J. Plescia, J. Felez, K. Kato, and E. F. Plow, "Role of cell-surface lysines in plasminogen binding to cells: identification of $\alpha$-enolase as a candidate plasminogen receptor," Biochemistry, vol. 30, no. 6, pp. 16821691, 1991.

[154] K. Nakajima, M. Hamanoue, N. Takemoto, T. Hattori, K. Kato, and S. Kohsaka, "Plasminogen binds specifically to $\alpha$-enolase on rat neuronal plasma membrane," Journal of Neurochemistry, vol. 63, no. 6, pp. 2048-2057, 1994.

[155] A. K. Ghosh and M. Jacobs-Lorena, "Surface-expressed enolases of Plasmodium and other pathogens," Memorias do Instituto Oswaldo Cruz, vol. 106, no. SUPPL. 1, pp. 85-90, 2011.

[156] P. A. Andreasen, R. Egelund, and H. H. Petersen, “The plasminogen activation system in tumor growth, invasion, and metastasis," Cellular and Molecular Life Sciences, vol. 57, no. 1, pp. 25-40, 2000.

[157] R. López-Alemany, C. Longstaff, S. Hawley et al., "Inhibition of cell surface mediated plasminogen activation by a monoclonal antibody against $\alpha$-enolase," American Journal of Hematology, vol. 72, no. 4, pp. 234-242, 2003.

[158] A. M. Floden, J. A. Watt, and C. A. Brissette, "Borrelia burgdorferi enolase is a surface-exposed plasminogen binding protein," PLoS One, vol. 6, no. 11, Article ID 27502, 2011.

[159] V. Pancholi, P. Fontan, and H. Jin, "Plasminogen-mediated group A streptococcal adherence to and pericellular invasion of human pharyngeal cells," Microbial Pathogenesis, vol. 35, no. 6, pp. 293-303, 2003.

[160] J. Sha, T. E. Erova, R. A. Alyea et al., "Surface-expressed enolase contributes to the pathogenesis of clinical isolate ssu of Aeromonas hydrophilaa," Journal of Bacteriology, vol. 191, no. 9, pp. 3095-3107, 2009.

[161] A. Derbise, Y. P. Song, S. Parikh, V. A. Fischetti, and V. Pancholi, "Role of the C-terminal lysine residues of streptococcal surface enolase in glu- and lys-plasminogenbinding activities of group a streptococci," Infection and Immunity, vol. 72, no. 1, pp. 94-105, 2004.

[162] S. Bergmann, M. Rohde, K. T. Preissner, and S. Hammerschmidt, "The nine residue plasminogen-binding motif of the pneumococcal enolase is the major cofactor of plasminmediated degradation of extracellular matrix, dissolution of fibrin and transmigration," Thrombosis and Haemostasis, vol. 94, no. 2, pp. 304-311, 2005.

[163] S. Bergmann, D. Wild, O. Diekmann et al., "Identification of a novel plasmin(ogen)-binding motif in surface displayed $\alpha$-enolase of Streptococcus pneumoniae," Molecular Microbiology, vol. 49, no. 2, pp. 411-423, 2003. 
[164] A. Itzek, C. M. Gillen, M. Fulde et al., "Contribution of plasminogen activation towards the pathogenic potential of oral streptococci," PLoS One, vol. 5, no. 11, Article ID e13826, 2010.

[165] I. Veiga-Malta, M. Duarte, M. Dinis, D. Tavares, A. Videira, and P. Ferreira, "Enolase from Streptococcus sobrinus is an immunosuppressive protein," Cellular Microbiology, vol. 6, no. 1, pp. 79-88, 2004.

[166] L. Avilan, M. Gualdron-Lopez, W. Quinones et al., "Enolase: a key player in the metabolism and a probable virulence factor of trypanosomatid parasites-perspectives for its use as a therapeutic target," Enzyme Research, vol. 2011, Article ID 932549, 14 pages, 2011.

[167] M. W. Cunningham, "Pathogenesis of group a streptococcal infections," Clinical Microbiology Reviews, vol. 13, no. 3, pp. 470-511, 2000.

[168] T. J. Mitchell, "The pathogenesis of streptococcal infections: from tooth decay to meningitis," Nature reviews. Microbiology, vol. 1, no. 3, pp. 219-230, 2003.

[169] F. Carlsson, C. Sandin, and G. Lindahl, "Human fibrinogen bound to Streptococcus pyogenes M protein inhibits complement deposition via the classical pathway," Molecular Microbiology, vol. 56, no. 1, pp. 28-39, 2005.

[170] J. Waldemarsson, M. Stålhammar-Carlemalm, C. Sandin, F. J. Castellino, and G. Lindahl, "Functional dissection of Streptococcus pyogenes M5 protein: the hypervariable region is essential for virulence," PLoS One, vol. 4, no. 10, Article ID e7279, 2009.

[171] U. Ringdahl, M. Svensson, A. C. Wistedt et al., "Molecular co-operation between protein PAM and streptokinase for plasmin acquisition by Streptococcus pyogenes," Journal of Biological Chemistry, vol. 273, no. 11, pp. 6424-6430, 1998.

[172] V. A. Fischetti, "Streptococcal M protein: molecular design and biological behavior," Clinical Microbiology Reviews, vol. 2, no. 3, pp. 285-314, 1989.

[173] G. N. Phillips, P. F. Flicker, and C. Cohen, "Streptococcal M protein: $\alpha$-Helical coiled-coil structure and arrangement on the cell surface," Proceedings of the National Academy of Sciences of the United States of America, vol. 78, no. 8 I, pp. 4689-4693, 1981.

[174] A. C. Wistedt, U. Ringdahl, W. Müller-Esterl, and U. Sjöbring, "Identification of a plasminogen-binding motif in PAM, a bacterial surface protein," Molecular Microbiology, vol. 18, no. 3, pp. 569-578, 1995.

[175] H. L. Wu, B. I. Chang, D. H. Wu et al., "Interaction of plasminogen and fibrin in plasminogen activation," Journal of Biological Chemistry, vol. 265, no. 32, pp. 19658-19664, 1990.

[176] M. D. Svensson, U. Sjöbring, and D. E. Bessen, "Selective distribution of a high-affinity plasminogen-binding site among group A streptococci associated with impetigo," Infection and Immunity, vol. 67, no. 8, pp. 3915-3920, 1999.

[177] A. Kalia and D. E. Bessen, "Natural selection and evolution of streptococcal virulence genes involved in tissue-specific adaptations," Journal of Bacteriology, vol. 186, no. 1, pp. 110121, 2004.

[178] W. S. Tillett and R. L. Garner, "The fibrinolytic activity of hemolytic streptococci," The Journal of Experimental Medicine, vol. 58, pp. 485-502, 1933.

[179] R. A. DeLa Cadena, K. J. Laskin, R. A. Pixley et al., "Role of kallikrein-kinin system in pathogenesis of bacterial cell wallinduced inflammation," American Journal of Physiology, vol. 260, no. 2, pp. G213-G219, 1991.
[180] F. S. KANTOR, "Fibrinogen precipitation by streptococcal m protein. I. identity of the reactants, and stoichiometry of the reaction," The Journal of Experimental Medicine, vol. 121, pp. 849-859, 1965.

[181] S. S. D'Costa and M. D. P. Boyle, "Interaction of a group A streptococcus within human plasma results in assembly of a surface plasminogen activator that contributes to occupancy of surface plasmin-binding structures," Microbial Pathogenesis, vol. 24, no. 6, pp. 341-349, 1998.

[182] M. D. Svensson, U. Sjöbring, F. Luo, and D. E. Bessen, "Roles of the plasminogen activator streptokinase and the plasminogen-associated $\mathrm{M}$ protein in an experimental model for streptococcal impetigo," Microbiology, vol. 148, no. 12, pp. 3933-3945, 2002.

[183] F. C. McKay, J. D. McArthur, M. L. Sanderson-Smith et al., "Plasminogen binding by group a streptococcal isolates from a region of hyperendemicity for streptococcal skin infection and a high incidence of invasive infection," Infection and Immunity, vol. 72, no. 1, pp. 364-370, 2004.

[184] L. L. Johnson, K. N. Berggren, F. M. Szaba, W. Chen, and S. T. Smiley, "Fibrin-mediated protection against infection-stimulated immunopathology," Journal of Experimental Medicine, vol. 197, no. 6, pp. 801-806, 2003.

[185] J. Sato, J. Schorey, V. A. Ploplis, E. Haalboom, L. Krahule, and F. J. Castellino, "The fibrinolytic system in dissemination and matrix protein deposition during a Mycobacterium infection," American Journal of Pathology, vol. 163, no. 2, pp. 517-531, 2003.

[186] H. Herwald, H. Cramer, M. Mörgelin et al., "M protein, a classical bacterial virulence determinant, forms complexes with fibrinogen that induce vascular leakage," Cell, vol. 116, no. 3, pp. 367-379, 2004.

[187] H. Herwald, M. Mörgelin, B. Dahlbäck, and L. Björck, "Interactions between surface proteins of Streptococcus pyogenes and coagulation factors modulate clotting of human plasma," Journal of Thrombosis and Haemostasis, vol. 1, no. 2, pp. 284291, 2003.

[188] A. Ben Nasr, H. Herwald, W. Muller-Esterl, and L. Bjorck, "Human kininogens interact with M protein, a bacterial surface protein and virulence determinant," Biochemical Journal, vol. 305, no. 1, pp. 173-180, 1995.

[189] A. Ben Nasr, H. Herwald, U. Sjobring, T. Renne, W. MüllerEsterl, and L. Bjorck, "Absorption of kininogen from human plasma by Streptococcus pyogenes is followed by the release of bradykinin," Biochemical Journal, vol. 326, no. 3, pp. 657660, 1997.

[190] L. M. F. Leeb-Lundberg, F. Marceau, W. Müller-Esterl, D. J. Pettibone, and B. L. Zuraw, "International union of pharmacology. XLV. Classification of the kinin receptor family: from molecular mechanisms to pathophysiological consequences," Pharmacological Reviews, vol. 57, no. 1, pp. 27-77, 2005.

[191] G. E. Kurpiewski, L. J. Forrester, B. J. Campbell, and J. T. Barrett, "Platelet aggregation by Streptococcus pyogenes," Infection and Immunity, vol. 39, no. 2, pp. 704-708, 1983.

[192] O. Shannon, E. Hertzén, A. Norrby-Teglund, M. Mörgelin, U. Sjöbring, and L. Björck, "Severe streptococcal infection is associated with $\mathrm{M}$ protein-induced platelet activation and thrombus formation," Molecular Microbiology, vol. 65, no. 5, pp. 1147-1157, 2007.

[193] L. I. Påhlman, M. Mörgelin, J. Eckert et al., "Streptococcal M protein: a multipotent and powerful inducer of inflammation," Journal of Immunology, vol. 177, no. 2, pp. 1221-1228, 2006. 
[194] L. I. Påhlman, A. I. Olin, J. Darenberg et al., "Soluble M1 protein of Streptococcus pyogenes triggers potent T cell activation," Cellular Microbiology, vol. 10, no. 2, pp. 404-414, 2008.

[195] K. Lähteenmäki, P. Kuusela, and T. K. Korhonen, "Plasminogen activation in degradation and penetration of extracellular matrices and basement membranes by invasive bacteria," Methods, vol. 21, no. 2, pp. 125-132, 2000.

[196] K. Lahteenmaki, R. Virkola, R. Pouttu, P. Kuusela, M. Kukkonen, and T. K. Korhonen, "Bacterial plasminogen receptors: in vitro evidence for a role in degradation of the mammalian extracellular matrix," Infection and Immunity, vol. 63, no. 9, pp. 3659-3664, 1995.

[197] J. L. Coleman, T. J. Sellati, J. E. Testa, R. R. Kew, M. B. Furie, and J. L. Benach, "Borrelia burgdorferi binds plasminogen, resulting in enhanced penetration of endothelial monolayers," Infection and Immunity, vol. 63, no. 7, pp. 2478-2484, 1995.

[198] C. R. W. Carneiro, E. Postol, R. Nomizo, L. F. L. Reis, and R. R. Brentani, "Identification of enolase as a laminin-binding protein on the surface of Staphylococcus aureus," Microbes and Infection, vol. 6, no. 6, pp. 604-608, 2004.

[199] B. Zavizion, J. H. White, and A. J. Bramley, "Staphylococcus aureus stimulates urokinase-type plasminogen activator expression by bovine mammary cells," Journal of Infectious Diseases, vol. 176, no. 6, pp. 1637-1640, 1997.

[200] J. Kolberg, A. Aase, S. Bergmann et al., "Streptococcus pneumoniae enolase is important for plasminogen binding despite low abundance of enolase protein on the bacterial cell surface," Microbiology, vol. 152, no. 5, pp. 1307-1317, 2006.

[201] C. Attali, C. Durmort, T. Vernet, and A. M. Di Guilmi, "The interaction of Streptococcus pneumoniae with plasmin mediates transmigration across endothelial and epithelial monolayers by intercellular junction cleavage," Infection and Immunity, vol. 76, no. 11, pp. 5350-5356, 2008.

[202] M. Wygrecka, L. M. Marsh, R. E. Morty et al., "Enolase-1 promotes plasminogen-mediated recruitment of monocytes to the acutely inflamed lung," Blood, vol. 113, no. 22, pp. 5588-5598, 2009.

[203] M. C. Chung, J. H. Tonry, A. Narayanan et al., "Bacillus anthracis interacts with plasmin(ogen) to evade C3bdependent innate immunity," PLoS One, vol. 6, no. 3, Article ID e18119, 2011.

[204] F. G. Sauer, M. A. Mulvey, J. D. Schilling, J. J. Martinez, and S. J. Hultgren, "Bacterial pili: molecular mechanisms of pathogenesis," Current Opinion in Microbiology, vol. 3, no. 1, pp. 65-72, 2000.

[205] P. Klemm and M. A. Schembri, "Bacterial adhesins: function and structure," International Journal of Medical Microbiology, vol. 290, no. 1, pp. 27-35, 2000.

[206] W. Shen, H. Steinruck, and A. Ljungh, "Expression of binding of plasminogen, thrombospondin, vitronectin, and fibrinogen, and adhesive properties by Escherichia coli strains isolated from patients with colonic diseases," Gut, vol. 36, no. 3, pp. 401-406, 1995.

[207] J. L. Benach, E. M. Bosler, and J. P. Hanrahan, "Spirochetes isolated from the blood of two patients with Lyme disease," New England Journal of Medicine, vol. 308, no. 13, pp. 740742, 1983.

[208] T. G. Schwan, J. Piesman, W. T. Golde, M. C. Dolan, and P. A. Rosa, "Induction of an outer surface protein on Borrelia burgdorferi during tick feeding," Proceedings of the National Academy of Sciences of the United States of America, vol. 92, no. 7, pp. 2909-2913, 1995.
[209] J. L. Coleman, E. J. Roemer, and J. L. Benach, "Plasmincoated Borrelia burgdorferi degrades soluble and insoluble components of the mammalian extracellular matrix," Infection and Immunity, vol. 67, no. 8, pp. 3929-3936, 1999.

[210] D. J. Grab, G. Perides, J. S. Dumler et al., "Borrelia burgdorferi, host-derived proteases, and the blood-brain barrier," Infection and Immunity, vol. 73, no. 2, pp. 1014-1022, 2005.

[211] J. L. Coleman, J. A. Gebbia, J. Piesman, J. L. Degen, T. H. Bugge, and J. L. Benach, "Plasminogen is required for efficient dissemination of B. burgdorferi in ticks and for enhancement of spirochetemia in mice," Cell, vol. 89, no. 7, pp. 1111-1119, 1997.

[212] G. Perides, L. M. Tanner-Brown, M. A. Eskildsen, and M. S. Klempner, "Borrelia burgdorferi induces matrix metalloproteinases by neural cultures," Journal of Neuroscience Research, vol. 58, no. 6, pp. 779-790, 1999.

[213] A. Kirchner, U. Koedel, V. Fingerle, R. Paul, B. Wilske, and H. W. Pfister, "Upregulation of matrix metalloproteinase9 in the cerebrospinal fluid of patients with acute Lyme neuroborreliosis," Journal of Neurology Neurosurgery and Psychiatry, vol. 68, no. 3, pp. 368-371, 2000.

[214] L. T. Hu, M. A. Eskildsen, C. Masgala et al., "Host metalloproteinases in lyme arthritis," Arthritis and Rheumatism, vol. 44, no. 6, pp. 1401-1410, 2001.

[215] J. A. Gebbia, J. L. Coleman, and J. L. Benach, "Borrelia spirochetes upregulate release and activation of matrix metalloproteinase gelatinase B (MMP-9) and collagenase 1 (MMP1) in human cells," Infection and Immunity, vol. 69, no. 1, pp. 456-462, 2001.

[216] A. K. Behera, C. M. Thorpe, J. M. Kidder, W. Smith, E. Hildebrand, and L. T. Hu, "Borrelia burgdorferi-induced expression of matrix metalloproteinases from human chondrocytes requires mitogen-activated protein kinase and janus kinase/signal transducer and activator of transcription signaling pathways," Infection and Immunity, vol. 72, no. 5, pp. 2864-2871, 2004.

[217] A. Santala, J. Saarinen, P. Kovanen, and P. Kuusela, "Activation of interstitial collagenase, MMP-1, by Staphylococcus aureus cells having surface-bound plasmin: a novel role of plasminogen receptors of bacteria," FEBS Letters, vol. 461, no. 3, pp. 153-156, 1999.

[218] J. A. Gebbia, J. C. Garcia Monco, J. L. Degen, T. H. Bugge, and J. L. Benach, "The plasminogen activation system enhances brain and heart invasion in murine relapsing fever borreliosis," Journal of Clinical Investigation, vol. 103, no. 1, pp. 81-87, 1999.

[219] A. Nordstrand, A. Shamaei-Tousi, A. Ny, and S. Bergström, "Delayed invasion of the kidney and brain by Borrelia crocidurae in plasminogen-deficient mice," Infection and Immunity, vol. 69, no. 9, pp. 5832-5839, 2001.

[220] M. Ringner, K. H. Valkonen, and T. Wadstrom, "Binding of vitronectin and plasminogen to Helicobacter pylori," FEMS Immunology and Medical Microbiology, vol. 9, no. 1, pp. 2934, 1994.

[221] M. Pantzar, A. Ljungh, and T. Wadström, "Plasminogen binding and activation at the surface of Helicobacter pylori CCUG 17874," Infection and Immunity, vol. 66, no. 10, pp. 4976-4980, 1998.

[222] A. Yarzábal, L. Avilán, K. Hoelzl, M. De Munoz, J. Puig, and I. Kansau, "A study of the interaction between Helicobacter pylori and components of the human fibrinolytic system," Brazilian Journal of Medical and Biological Research, vol. 33, no. 9, pp. 1015-1021, 2000. 
[223] A. Varro, P. J. M. Noble, D. M. Pritchard et al., "Helicobacter pylori Induces plasminogen activator inhibitor 2 in gastric epithelial cells through nuclear factor- $\kappa \mathrm{B}$ and rhoa: implications for invasion and apoptosis," Cancer Research, vol. 64, no. 5, pp. 1695-1702, 2004.

[224] M. Colucci, M. R. Rossiello, A. Pentimone et al., "Changes in coagulation-fibrinolysis balance in blood mononuclear cells and in gastric mucosa from patients with Helicobacter pylori infection," Thrombosis Research, vol. 116, no. 6, pp. 471-477, 2005.

[225] D. Grenier, "Degradation of host protease inhibitors and activation of plasminogen by proteolytic enzymes from Porphyromonas gingivalis and Treponema denticola," Microbiology, vol. 142, no. 4, pp. 955-961, 1996.

[226] M. Kukkonen, K. Lähteenmäki, M. Suomalainen et al., "Protein regions important for plasminogen activation and inactivation of $\alpha 2$-antiplasmin in the surface protease Pla of Yersinia pestis," Molecular Microbiology, vol. 40, no. 5, pp. 1097-1111, 2001.

[227] J. Travis, J. Potempa, and H. Maeda, "Are bacterial proteinases pathogenic factors?" Trends in Microbiology, vol. 3, no. 10, pp. 405-407, 1995.

[228] K. Lähteenmäki, M. Kukkonen, and T. K. Korhonen, “The Pla surface protease/adhesin of Yersinia pestis mediates bacterial invasion into human endothelial cells," FEBS Letters, vol. 504, no. 1-2, pp. 69-72, 2001.

[229] J. D. Goguen, T. Bugge, and J. L. Degen, "Role of the pleiotropic effects of plasminogen deficiency in infection experiments with plasminogen-deficient mice," Methods, vol. 21, no. 2, pp. 179-183, 2000.

[230] V. Hurmalainen, S. Edelman, J. Antikainen, M. Baumann, K. Lähteenmäki, and T. K. Korhonen, "Extracellular proteins of Lactobacillus crispatus enhance activation of human plasminogen," Microbiology, vol. 153, no. 4, pp. 1112-1122, 2007.

[231] M. Candela, E. Biagi, M. Centanni et al., "Bifidobacterial enolase, a cell surface receptor for human plasminogen involved in the interaction with the host," Microbiology, vol. 155, no. 10, pp. 3294-3303, 2009.

[232] J. Antikainen, V. Kuparinen, K. Lähteenmäki, and T. K. Korhonen, "Enolases from gram-positive bacterial pathogens and commensal lactobacilli share functional similarity in virulence-associated traits," FEMS Immunology and Medical Microbiology, vol. 51, no. 3, pp. 526-534, 2007. 

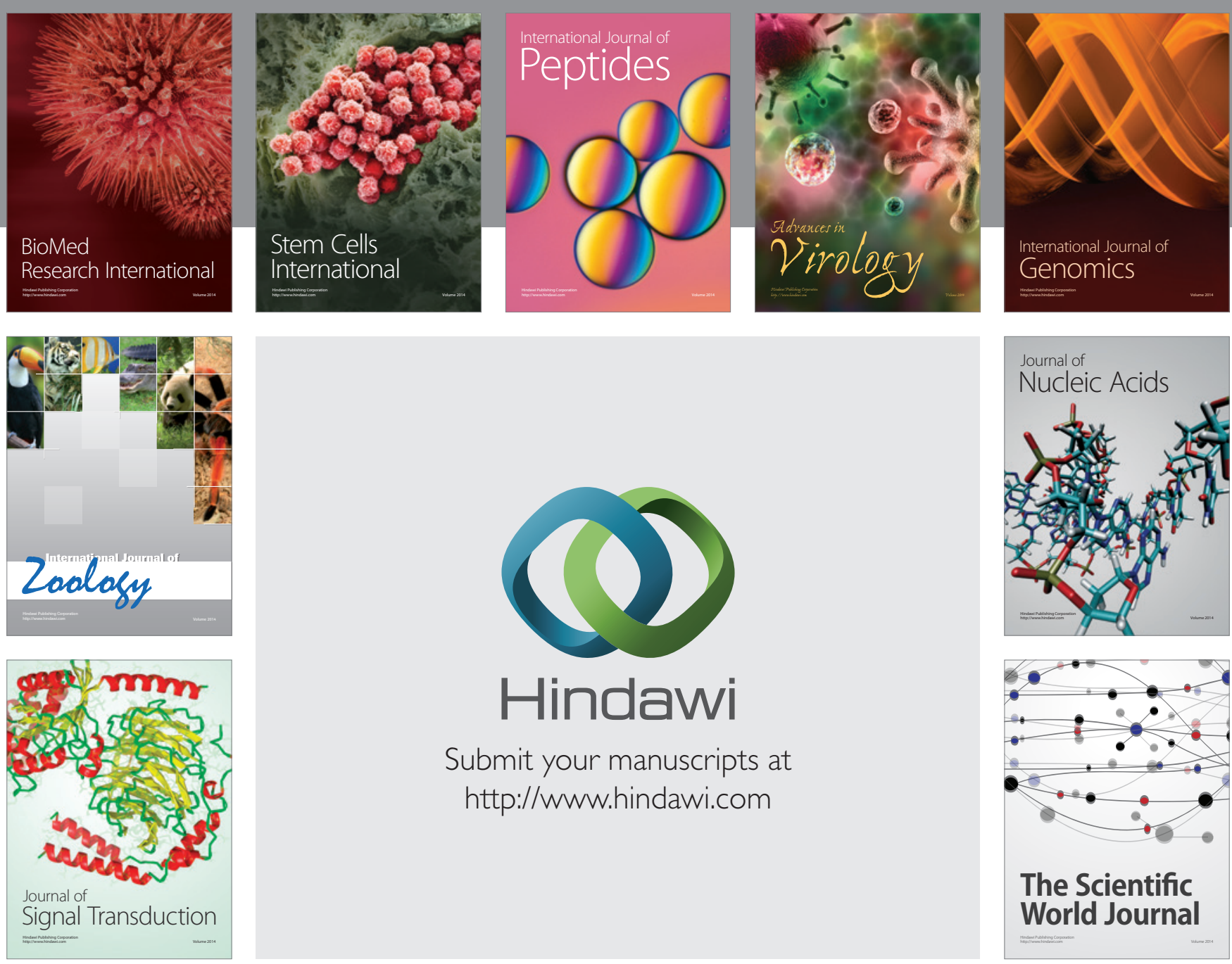

Submit your manuscripts at

http://www.hindawi.com
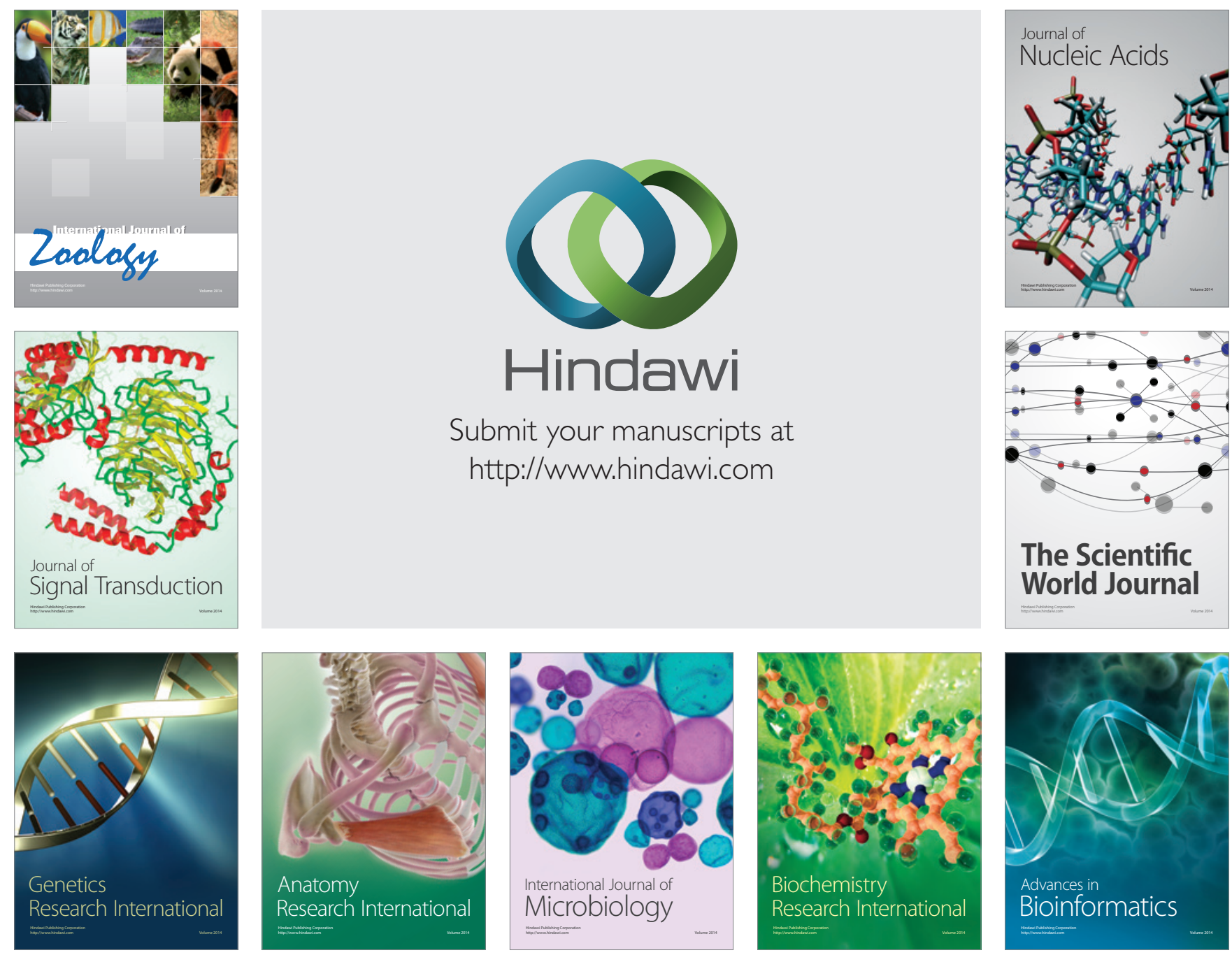

The Scientific World Journal
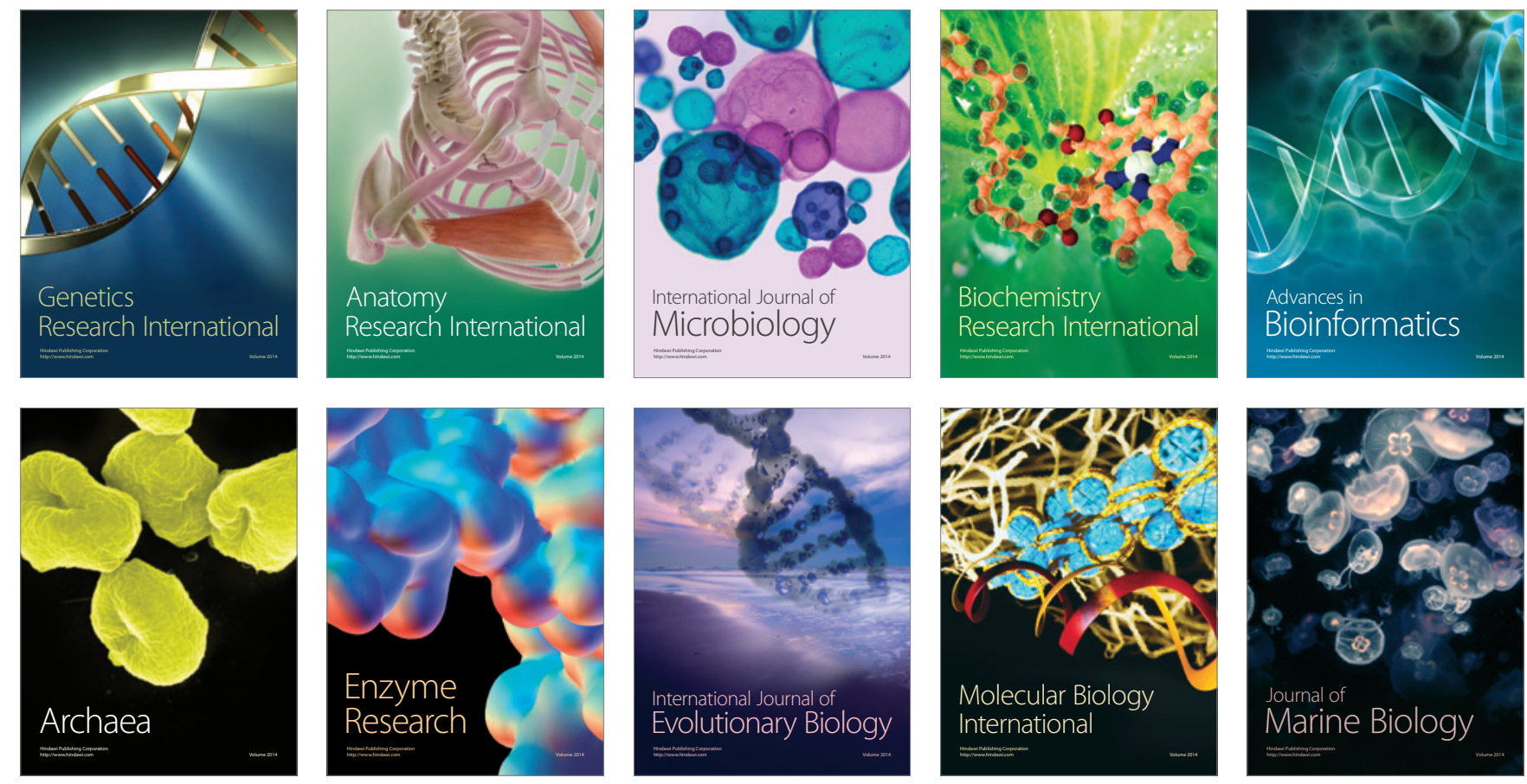